\title{
The Met Office Unified Model Global Atmosphere 3.0/3.1 and JULES Global Land 3.0/3.1 configurations
}

\author{
D. N. Walters, M. J. Best, A. C. Bushell, D. Copsey, J. M. Edwards, P. D. Falloon, C. M. Harris, A. P. Lock, \\ J. C. Manners, C. J. Morcrette, M. J. Roberts, R. A. Stratton, S. Webster, J. M. Wilkinson, M. R. Willett, I. A. Boutle, \\ P. D. Earnshaw, P. G. Hill, C. MacLachlan, G. M. Martin, W. Moufouma-Okia, M. D. Palmer, J. C. Petch, \\ G. G. Rooney, A. A. Scaife, and K. D. Williams \\ Met Office, FitzRoy Road, Exeter, EX1 3PB, UK
}

Received: 20 April 2011 - Published in Geosci. Model Dev. Discuss.: 17 June 2011

Revised: 26 September 2011 - Accepted: 14 October 2011 - Published: 26 October 2011

\begin{abstract}
We describe Global Atmosphere 3.0 (GA3.0): a configuration of the Met Office Unified Model (MetUM) developed for use across climate research and weather prediction activities. GA3.0 has been formulated by converging the development paths of the Met Office's weather and climate global atmospheric model components such that wherever possible, atmospheric processes are modelled or parametrized seamlessly across spatial resolutions and timescales. This unified development process will provide the Met Office and its collaborators with regular releases of a configuration that has been evaluated, and can hence be applied, over a variety of modelling régimes. We also describe Global Land 3.0 (GL3.0): a configuration of the JULES community land surface model developed for use with GA3.0.

This paper provides a comprehensive technical and scientific description of the GA3.0 and GL3.0 (and related GA3.1 and GL3.1) configurations and presents the results of some initial evaluations of their performance in various applications. It is to be the first in a series of papers describing each subsequent Global Atmosphere release; this will provide a single source of reference for established users and developers as well as researchers requiring access to a current, but trusted, global MetUM setup.
\end{abstract}

\section{Introduction}

The Met Office Unified Model ${ }^{\mathrm{TM}}$ (MetUM) is a highly flexible atmospheric model that was designed from its inception to be used for both climate research and Numerical Weather Prediction (NWP) activities in both global and limited area

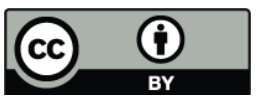

Correspondence to: D. N. Walters (david.walters@metoffice.gov.uk) configurations (Cullen, 1993). For nearly twenty years, this has provided the Met Office and its collaborators with the benefit of a single technical infrastructure, dynamical core and collection of atmospheric parametrizations and has allowed them to develop modelling systems efficiently without the duplication of effort on common programming tasks. This technical efficiency also extends to the scientific development of the model. Climate models are being run at ever higher resolution and applied to problems beyond the prediction of mean climate states, such as the frequency and severity of extreme weather events (Huntingford et al., 2003). This requires the accurate modelling of mesoscale systems, which has long been the remit of NWP forecasting. Conversely, to consistently improve the quality of weather forecasts, global and regional NWP models are starting to employ more complexity and modelling elements of the Earth System that have previously been the reserve of climate modelling, such as atmospheric composition (Milton et al., 2008) and detailed modelling of the water cycle (Balsamo et al., 2011). Collaboration between climate and weather scientists and the use of a common atmospheric model aids users of the MetUM to make these developments in an efficient manner.

As well as the efficiency of central code development, using the MetUM allows the Met Office to take advantage of the recognised synergies between climate and NWP modelling (Martin et al., 2010; Senior et al., 2010). By studying the same model formulation across a range of temporal scales one can distinguish systematic biases that develop on very short timescales due to errors in rapidly responding parametrizations (e.g. clouds and precipitation) from those that develop due to more slowly evolving elements such as the soil moisture content in the land surface model. Studying the same model across different resolutions also allows one to investigate the sensitivity of processes such as tropical

Published by Copernicus Publications on behalf of the European Geosciences Union. 
cyclone formation to the resolved spatial scales (Heming, 2010) and the efficiency of parametrization schemes in modelling unresolved processes such as atmospheric convection (Lean et al., 2008). Finally, verifying a model against observations, atmospheric analyses and climatologies greater exposes its deficiencies and leads to a more robust formulation.

For this reason, the Met Office has kept the development paths of the global forecast models within its operational NWP suite and the Met Office Hadley Centre's climate and seasonal forecasting models roughly aligned. Major developments introduced in one set of models are usually adopted by the other after only a short delay (e.g. Martin et al., 2006; Milton et al., 2005). This process is hampered, however, when developments that become well established in one context prove deficient in another, which can lead to either the inefficient development of a more general solution or a divergence of the configurations. To improve this situation, the Met Office has recently formalised the coordination of these development paths by merging them into a single "Global Atmosphere" configuration. This is a common choice of scientific options that will be applied to all of the Met Office's global atmospheric MetUM components. A similar approach is planned for other components of the Earth System such as the land surface, ocean, sea-ice and atmospheric chemistry and aerosols. The combined Global Atmosphere is a logical progression from the decision to develop a single atmospheric formulation for use across the Met Office Hadley Centre's climate models: the HadGEM3 (Hadley Centre Global Environmental Model version 3) family. In recognition of this, the atmospheric components of the two operationally used climate modelling systems previously known as HadGEM3-r1.1 (Hewitt et al., 2011) and HadGEM3-r4.0 (Arribas et al., 2011) have been labelled GA1.0 and GA2.0, respectively.

This paper describes the first such MetUM configuration developed for use in short-range NWP as well as climate modelling: Global Atmosphere 3.0 (GA3.0). It also describes a configuration of the JULES (Joint UK Land Environment Simulator, Best et al., 2011; Clark et al., 2011) land surface model developed for use with GA3.0; this is labelled Global Land 3.0 (GL3.0). In the following section we describe precisely what we mean by the Global Atmosphere configuration, the vision of how this could be used by the Met Office and the wider MetUM community and our plans for a more open development process. Again, this is designed as a general template that could be followed for other Earth System components. In Sect. 3 we scientifically describe both GA3.0 and GL3.0, whilst in Sect. 4 we provide a more detailed description of some of the major developments made since GA2.0 and its accompanying Global Land configuration GL2.0. Although these configurations are being assessed in NWP trials and case studies, the configurations used in the first operational global NWP implementation based on GA3.0 and GL3.0 retain a small number of longstanding differences from the climate model; we label these GA3.1 and GL3.1. These differences and a discussion of the motivations behind them are included in Sect. 5, Finally, we present some initial results from assessments of the configurations in Sect. 6 and summarise our current position in Sect. 7.

\section{The "Global Atmosphere" configuration}

\subsection{Definition of the Global Atmosphere}

The principle of the Global Atmosphere configuration follows that set out for the atmospheric component of the HadGEM3 family in Hewitt et al. (2011), but extended to include short-range NWP configurations. The Global Atmosphere is a single choice of dynamical core, atmospheric parametrizations, and options therein, applied to an atmospheric MetUM component which may well itself be part of a larger system. For example, the global climate modelling system HadGEM3-AO currently uses a MetUM Global Atmosphere component coupled internally to a JULES Global Land component and externally to the NEMO ocean model (Madec, 2008) and the Los Alamos sea ice (CICE) model (Hunke and Lipscombe, 2008) via the OASIS coupler (Valcke, 2006). The Met Office's short-range NWP forecasting system currently uses the MetUM Global Atmosphere and JULES Global Land initialised via a 4D-Var data assimilation cycle (Rawlins et al., 2007), a soil moisture analysis system (Best and Maisey, 2002) and uses fixed seasurface temperature (SST) and sea ice fields from the OSTIA (Operational Sea-surface Temperature and sea Ice Analysis) system (Donlon et al., 2011).

To illustrate the breadth of potential applications, the following is a list of operational or production systems in which the Met Office is using or plans to use Global Atmosphere configurations:

- Deterministic NWP (6 days): atmosphere/land-only, started from 4D-Var data assimilation and soil moisture, snow and SST analyses. Produces global weather forecasts and boundary conditions for limited area NWP models;

- Ensemble prediction system (15 days): 24 members with stochastic physics parametrizations initialised from perturbed deterministic analyses and using persisted SST anomalies (Bowler et al., 2008). Provides probabilistic global weather forecasts and boundary conditions for the regional ensemble;

- Monthly forecasting system (60 days): Lagged ensemble (28 members per week) of coupled MetUM/JULES/NEMO/CICE models with stochastic physics parametrizations initialised from deterministic atmospheric and ocean model analyses. Output is bias-corrected using an extensive set of hindcasts; 
- Seasonal forecasting system (210 days): Extension of the monthly system in which each simulation runs for 7 months. A lagged 42-member ensemble is updated every week by including all forecasts run in the previous 21 days (Arribas et al., 2011);

- Decadal prediction system (10 yr): using coupled MetUM/JULES/NEMO/CICE models and based on that discussed in Smith et al. (2007);

- HadGEM3-A Atmosphere/land-only climate assessments/inter-comparisons (30 yr);

- Continent-scale regional climate model assessments/inter-comparisons (30 yr) or climate change projections (up to $150 \mathrm{yr}$ );

- HadGEM3-AO MetUM/JULES/NEMO/CICE coupled climate integrations for assessment and climate change projections (100 s of years);

- Planned HadGEM3 Earth System model (100s of years).

Outside the Met Office, both the MetUM and JULES are widely utilised within both UK and international academia as well as being used operationally by research institutes and meteorological services across the globe. Each user will have their own projects, systems and frameworks in which they wish to run the models; our aim is to provide technically and scientifically robust configurations that our collaborators can contribute to and use with confidence.

To be applicable across this variety of systems, the physical formulation of the Global Atmosphere must be independent of horizontal resolution. The MetUM contains a few options and input parameters that have an implicit resolution dependence, so these also remain outside our definition of the Global Atmosphere. Ideally, the configuration would also be independent of vertical resolution, allowing users to add refinement to the regions of the atmosphere in which they are particularly interested (e.g. see discussion in Senior et al., 2010). In practice, however, the performance of parametrizations in the troposphere is still sensitive to vertical resolution, so currently we are only assessing GA3.0 in systems with a common vertical tropospheric resolution, which is described in Sect. 3.1. In the stratosphere and above, however, there is less constraint on the vertical resolution and we use different level sets in different applications. Current research plans include an investigation into the benefits of increased vertical resolution in different layers of the atmosphere across all timescales, which may lead to some refinement in the level sets used in future Global Atmosphere releases.

Another field where the variety of applications requires flexibility in the configuration is in the interaction between the atmosphere and other components of the Earth System. One such example is the treatment of atmospheric chemistry and aerosols. Full Earth System models (e.g., HadGEM2ES, described in Collins et al., 2008) represent the emission, transport, radiative impact and chemical interaction of atmospheric aerosols and trace gases as well as their impact on other elements of the Earth System such as the biosphere. Lower down the hierarchy of complexity are climate models that include a full suite of prognostic atmospheric aerosols but little atmospheric chemistry, such as HadGEM2AO (HadGEM2 Development Team: Martin et al., 2011), whilst short-range NWP models currently tend not to include prognostic aerosol at all. For this reason, we choose to consider atmospheric chemistry and aerosols as a component of the Earth System separate to the Global Atmosphere. To maintain traceability through this hierarchy of models, however, we treat their interaction with atmospheric physics schemes as consistently as possible. For example, using too simple an aerosol climatology in NWP models has previously led to regional or seasonal biases in the radiation budget (Haywood et al., 2005), which have recently been partly overcome by introducing a set of three-dimensional, seasonal, speciated aerosol climatologies derived from the prognostic fields of a long climate integration.

Finally, from a technical stance, the Global Atmosphere is independent of MetUM code version. Assessments of GA3.0 and GA3.1 have been performed at MetUM vn7.7 and vn7.8; because the vast majority of options within the model are backward compatible, future applications may also use code vn7.9 and beyond. The use of older code versions is more complicated, since some of the options in a given GA configuration may not be available in older releases, but for minor changes it is possible to introduce branches to the main code trunk that include the newer code ${ }^{1}$. We only plan to support a given Global Atmosphere configuration across a handful of MetUM code releases, which means that the extended use of stable configurations for major climate change research activities is likely to require the continued use of an older code base.

\subsection{The Global Atmosphere development process}

Global Atmosphere configurations are developed over an annual cycle in which any potential enhancements are tested for impact across all timescales. These changes are combined into a small number of test configurations and then a final frozen configuration. This is then evaluated through a full set of climate assessments and NWP trials including coupling to other components of the Earth System and including non-production systems such as very high resolution climate simulations and NWP case studies across a whole range of

\footnotetext{
${ }^{1}$ For example, a small proportion of the code for GA3.0 is not available in the central trunk at vn7.7. Because it is best practice to only use centrally lodged code, wherever possible we limit this to code reviewed and lodged at a later MetUM version and changes to "parameter" statements that can be introduced as user set options in a later release.
} 
resolutions. If the configuration performs sufficiently across these tests, it is introduced in subsequent upgrades to the Met Office systems described above and "released" for use by the wider community. If some changes to the configuration are required, however, due to insufficient performance in a particular system or set of systems, then this is overcome by the introduction of a branch to the Global Atmosphere development trunk. An example of this is the GA3.1 configuration that the Met Office will be implementing - and recommending for external use - in NWP systems. This branch configuration, however, is due to a continued small set of longstanding differences between our NWP and climate models rather than deficiencies in any new developments. Although we will not be using GA3.0 in operational NWP systems, we are assessing its performance in NWP trialling. This is important not only in understanding how best to resolve these differences over the coming year, but also because we will test the performance of each new development against the Global Atmosphere trunk and not its branches; this will reduce the probability of additional changes being introduced with compensating errors that make it harder to remove the necessity for a branch. Finally, the Met Office has introduced an open development process and will encourage the scrutiny and participation of MetUM collaborators. We believe that inviting the wider MetUM community to contribute to the Global Atmosphere configuration will add to its scientific integrity, encourage its use and accelerate its improvement. The same argument also stands for the other components of the Earth System.

In the following sections, we provide scientific descriptions of GA3.0 and GL3.0. For brevity, we refer to the coupled Global Atmosphere and Global Land configurations as GA3.0/GL3.0. Major developments since GA2.0/GL2.0 are discussed in more detail in Sect. 4.

\section{Global Atmosphere 3.0 and Global Land 3.0}

\subsection{Dynamical formulation and discretization}

The MetUM's dynamical core uses a semi-implicit semiLagrangian formulation to solve the non-hydrostatic, fullycompressible deep atmosphere equations of motion (Davies et al., 2005). The primary dry atmospheric prognostics are the three-dimensional wind components, potential temperature, Exner pressure, and density, whilst moist prognostics such as specific humidity and prognostic cloud fields as well as other atmospheric loadings are advected as free tracers. These prognostic fields are discretized horizontally onto a regular longitude/latitude grid with Arakawa C-grid staggering (Arakawa and Lamb, 1977), whilst vertical decomposition is done via Charney-Phillips staggering (Charney and Phillips, 1953) using terrain-following hybrid height coordinates.
By convention, global configurations are defined on $2 n$ longitudes and $1.5 n+1$ latitudes of scalar grid-points with scalar and zonal wind variables at the north and south poles. This choice makes the grid-spacing approximately isotropic in the mid-latitudes and means that the integer $n$, which represents the maximum number of zonal 2 grid-point waves that can be represented by the model, uniquely defines its horizontal resolution; a model with $n=96$ is said to be N96 resolution. Limited area configurations use a rotated longitude/latitude grid with the pole rotated so that the grid's equator runs through the centre of the model domain.

In the vertical, the majority of climate configurations we have assessed use the high-top 85 level set discussed in Hewitt et al. (2011). We label this L85 $\left(50_{t}, 35_{\mathrm{s}}\right)_{85}$, which refers to the fact that it has 50 levels below $18 \mathrm{~km}$ (and hence at least sometimes in the troposphere), 35 levels above this (and hence solely in or above the stratosphere) and a fixed model lid $85 \mathrm{~km}$ above the surface. Limited area climate simulations use a reduced 63 level set, L63(50, 13 $)_{40}$, which has the same 50 levels below $18 \mathrm{~km}$, with only 13 above and a lower model top at $40 \mathrm{~km}$. Finally, NWP configurations use a 70 level set, $\operatorname{L70}\left(50_{\mathrm{t}}, 20_{\mathrm{s}}\right)_{80}$ which has an almost identical 50 levels below $18 \mathrm{~km}$, a model lid at $80 \mathrm{~km}$, but has a reduced stratospheric resolution compared to $\mathrm{L} 85\left(50_{\mathrm{t}}, 35_{\mathrm{s}}\right)_{85}$. Although we have used a range of vertical resolutions in the stratosphere, a consistent tropospheric vertical resolution is used throughout as noted in Sect. 2.

\subsection{Solar and terrestrial radiation}

Shortwave (SW) radiation from the Sun is absorbed in the atmosphere and at the Earth's surface and provides the energy to drive the atmospheric circulation. Longwave (LW) radiation is emitted from the planet into space and also redistributes heat within the atmosphere. These processes are parametrized via the radiation scheme, which provides prognostic atmospheric temperature increments and surface fluxes and additional diagnostic fluxes.

The radiation scheme of Edwards and Slingo (1996) is used with a configuration based on Cusack et al. (1999) with a number of significant updates. The correlated- $k$ method is used for gaseous absorption with 6 bands in the SW and 9 bands in the LW. The method of equivalent extinction (Edwards, 1996) is used for minor gases in each band. Gaseous absorption coefficients are generated using the HITRAN 2001 spectroscopic database (Rothman et al., 2003) with updates up to 2003 . The water vapour continuum is represented using version 2.4 of the Clough-Kneizys-Davies (CKD) model (Clough et al., 1989; Mlawer et al., 1999). 21 $k$-terms are used for the major gases in the SW bands. Absorption by water vapour $\left(\mathrm{H}_{2} \mathrm{O}\right)$, ozone $\left(\mathrm{O}_{3}\right)$, carbon dioxide $\left(\mathrm{CO}_{2}\right)$ and oxygen $\left(\mathrm{O}_{2}\right)$ is included. The treatment of $\mathrm{O}_{3}$ absorption is as described in Zhong et al. (2008). The solar spectrum uses data from Lean (2000) at wavelengths shorter than $735 \mathrm{~nm}$ with the Kurucz and Bell (1995) spectrum at 
longer wavelengths. $47 k$-terms are used for the major gases in the $\mathrm{LW}$ bands. Absorption by $\mathrm{H}_{2} \mathrm{O}, \mathrm{O}_{3}, \mathrm{CO}_{2}, \mathrm{CH}_{4}$, nitrous oxide $\left(\mathrm{N}_{2} \mathrm{O}\right)$, CFC-11 $\left(\mathrm{CCl}_{3} \mathrm{~F}\right), \mathrm{CFC}-12\left(\mathrm{CCl}_{2} \mathrm{~F}_{2}\right)$ and $\mathrm{HFC134a}\left(\mathrm{CH}_{2} \mathrm{FCF}_{3}\right)$ is included. For climate simulations, the atmospheric concentrations of CFC-12 and HFC134a are adjusted to represent absorption by all the remaining trace halocarbons. The treatment of $\mathrm{CO}_{2}$ and $\mathrm{O}_{3}$ absorption is as described in Zhong and Haigh (2000) to provide accurate stratospheric heating.

Absorption and scattering by the following categories of aerosol, either prognostic or climatological, are included in both the SW and LW: ammonium sulphate, mineral dust, seasalt, biomass-burning, fossil-fuel black carbon, fossil-fuel organic carbon, and secondary organic (biogenic) aerosols. The parametrization of cloud droplets is described in Edwards and Slingo (1996) using the method of "thick averaging". Padé fits are used for the variation with effective radius, which is computed from the number of cloud droplets. When using prognostic aerosol, this is derived from the aerosol concentrations (Jones et al., 2001), whilst when using either no aerosol or climatological aerosol, this is assumed to be $100 \mathrm{~cm}^{-3}$ for maritime airmasses and $300 \mathrm{~cm}^{-3}$ for continental airmasses. The parametrization of ice crystals is described in Edwards et al. (2007). Full treatment of scattering is used in both the SW and LW. The sub-grid cloud structure is represented using the Monte-Carlo Independent Column Approximation (McICA) as described in Hill et al. (2011), with optimal sampling using 6 extra terms in the LW and 10 in the SW for the reduction of random noise.

Full radiation calculations are made every $3 \mathrm{~h}$ using the instantaneous cloud fields and a mean solar zenith angle for the following $3 \mathrm{~h}$ period. Corrections for the change in solar zenith angle on every model timestep and the change in cloud fields every hour are made as described in Manners et al. (2009). The land surface is prescribed a global emissivity of 0.97 whilst the albedo is set by the land surface model. The direct SW flux at the surface is corrected for the angle and aspect of the topographic slope as described in Manners (2011). The albedo of the sea surface uses a modified version of the parametrization from Barker and $\mathrm{Li}$ (1995) with a varying spectral dependence.

\subsection{Large scale precipitation}

The formation and evolution of precipitation due to grid scale processes is the responsibility of the large scale precipitation - or microphysics - scheme, whilst small scale precipitating events are handled by the convection scheme. The microphysics scheme has prognostic input fields of heat and moisture, which it modifies in turn. The microphysics used in GA3.0 is based on Wilson and Ballard (1999), with extensive modifications. The particle-size distribution has been modified from a Marshall and Palmer (1948) distribution to include an intercept based on rain rate and the minimum cloud liquid content for autoconversion to occur has been altered from the original Tripoli and Cotton (1980) formulation to a liquid content where the number of drops over $20 \mu \mathrm{m}$ is $1000 \mathrm{~cm}^{-3}$. Both these modifications have been described in Abel et al. (2010). In addition, we have used the fall velocities of Abel and Shipway (2007), which allow a better representation of the drizzle drop spectrum. This has been combined with a prognostic rain formulation, which allows three-dimensional advection of the precipitation particles. We also make use of multiple sub-timesteps of the precipitation scheme, as in Posselt and Lohmann (2008), to achieve a reduction in surface drizzle rates, with one subtimestep for every two minutes of the model timestep. These new modifications are described in more detail in Sect. 4. When prognostic aerosols are used, the aerosol mass mixing ratios provide the cloud droplet number for autoconversion, according to the formulae of Jones et al. (1994). In GA3.0, the aerosols which provide the droplet number are sulphur, soot, biomass and fossil fuels/organic carbon. When using either no aerosol or climatological aerosol, the cloud droplet number assumes the same land/sea split as in the radiation scheme.

\subsection{Large scale cloud}

Clouds appear on sub-grid scales well before the humidity averaged over the size of a model grid-box reaches saturation. A cloud parametrization scheme is therefore required to determine the fraction of the grid-box which is covered by cloud and the amount and phase of condensed water contained in those clouds. The formation of clouds will convert water vapour into liquid or ice and release latent heat. The cloud cover and liquid and ice water contents are then used by the radiation scheme to calculate the radiative impact of the clouds and by the microphysics scheme to calculate whether any precipitation has formed. GA3.0 uses the MetUM's prognostic cloud fraction and prognostic condensate (PC2) scheme (Wilson et al., 2008a,b). This uses three prognostic variables for humidity mixing ratio: water vapour, liquid and ice and a further three prognostic variables for cloud fraction: liquid, ice and total. The total cloud fraction is not necessarily equal to the sum of the other two due to the presence of mixed-phase regions. The following atmospheric processes can modify the cloud fields: shortwave radiation, longwave radiation, boundary layer processes, convection, precipitation, small scale mixing, advection and pressure changes due to large scale vertical motion. The convection scheme calculates increments to the prognostic liquid and ice water contents by detraining condensate from the convective plume, whilst the cloud fractions are updated using the non-uniform forcing method of Bushell et al. (2003). One advantage of the prognostic approach is that clouds can be transported away from where they were created. For example, anvils detrained from convection can persist and be advected downstream long after the convection itself has ceased. Additionally, cloud budget tendency terms 
from the prognostic cloud scheme can be analysed to determine how each of the physical processes in the model is contributing to the evolution of the cloud fields (Morcrette and Petch, 2010).

\subsection{Orographic gravity wave drag}

The effect of local and mesoscale orographic features (individual hills through to small mountain ranges) not resolved by the mean orography must be parametrized. The smallest scales, where buoyancy effects are not important, are represented by an effective roughness parametrization in which the roughness length for momentum used by the boundary layer scheme is increased over orography (Gregory et al., 1998). The effects of the remainder of the subgrid orography (on scales where buoyancy effects are important) are parametrized by a flow blocking and gravity wave drag parametrization. The scheme is based on Webster et al. (2003) and accounts for drag effects due to sub-grid orography in stable conditions. The sub-grid orography is described in terms of its amplitude, which is proportional to the standard deviation of the source orography in a model grid-box, and its anisotropy, i.e. how ridge-like the sub-grid orography is. The total surface stress is proportional to the bulk lowlevel winds and stability, and is determined using a simple linear hydrostatic expression; idealised modelling (e.g. Wells et al., 2005) suggests this captures the total surface stress reasonably well. The low-level Froude number is then used to partition the total stress into gravity wave and flow blocking components due to flow over and around the orography, respectively. The flow blocking drag is diagnosed assuming a linear decrease in the stress over the depth of the subgrid orography, whilst the gravity wave stress is launched upwards and a drag exerted at levels where wave breaking or wave saturation is diagnosed. Typically, in excess of $90 \%$ of the global mean of the total surface stress is attributed to low-level flow blocking. The drag is applied as explicit increments to the model wind fields, so a numerical limiter is imposed on the flow blocking drag to ensure the numerical stability of the scheme (Brown and Webster, 2004).

\subsection{Non-orographic gravity wave drag}

Orography is just one forcing mechanism for gravity waves; others (e.g. convection, fronts, jets) can force gravity waves with non-zero phase-speed. The temporal and spatial resolution of a given model configuration dictate the scale of gravity waves sustained explicitly; accelerations by the remainder are generated by a sub-grid parametrization scheme (Scaife et al., 2002). It is important to represent momentum deposition by breaking of such waves in the upper stratosphere and mesosphere because they drive a circulation that opposes radiative equilibrium in zonal mean wind and temperature structure at these heights. Also, models without such schemes report a need for much finer vertical resolution to represent a realistic quasi-biennial oscillation in the tropics. The scheme, based on Warner and McIntyre (2001), treats a spectrum (against vertical wavenumber) of gravity waves in 4 azimuthal directions (W, N, E, S) and represents the processes of wave generation, conservative propagation and dissipation by critical-level filtering and wave saturation. The simplest wave generation (Scaife et al., 2002) is to launch, in the lower troposphere, a vertical flux of horizontal gravity wave momentum that totals a globally invariant $2.47 \mathrm{mPa}$ in each direction. This represents order $10 \%$ of the saturation spectrum at launch height. Isotropic fluxes guarantee zero total momentum at launch height and momentum conservation is also enforced at the model upper boundary by imposing an "opaque lid", i.e. a condition of zero vertical wave flux passing up out of the top layer. The launch spectrum has the two-part form of Warner and McIntyre (2001) with low wavenumber cut-off and spectrum peak located at wavelengths $20 \mathrm{~km}$ and $4.3 \mathrm{~km}$, respectively. It is linear for wavenumbers up to the peak, beyond which it has the inverse cubic tail characteristic of saturation. The launched spectra propagate upwards conservatively, responding to variations in mean wind speed (Doppler shift) and reducing density, under the assumed mid-frequency approximation to the dispersion equation. Hence wave reflection is not modelled, though its effect is partly accounted for by a reduced launch spectrum amplitude. Momentum deposition occurs as the integrated flux reduces due to erosion of each transformed launch spectrum that exceeds the locally evaluated saturation spectrum. As applied, the calculation of integrated flux filtering through individual levels first modifies the original launch spectrum to limit flux propagating through the level to below local saturation, then maintains a form of causality by requiring that integrated flux leaving through the top of a layer never exceeds the integrated flux which entered through the layer base.

\subsection{Atmospheric boundary layer}

Turbulent motions in the atmosphere are not resolved by global atmospheric models, but are important to parametrize in order to give realistic vertical structure in the thermodynamic and wind profiles. Although referred to as the "boundary layer" scheme, this parametrization represents mixing over the full depth of the troposphere. The scheme is that of Lock et al. (2000) with the modifications described in Lock (2001) and Brown et al. (2008). It is a first-order turbulence closure mixing adiabatically conserved variables. For unstable boundary layers diffusion coefficients ( $K$-profiles) are specified functions of height within the boundary layer, related to the strength of the turbulence forcing. Two separate $K$-profiles are used, one for surface sources of turbulence (surface heating and wind shear) and one for cloudtop sources (radiative and evaporative cooling). The existence and depth of unstable layers is diagnosed initially by moist adiabatic parcels and then adjusted to ensure that the 
buoyancy consumption of turbulence kinetic energy is limited. This can permit the cloud layer to decouple from the surface (Nicholls, 1984). If cumulus convection is diagnosed (through comparison of cloud and sub-cloud layer moisture gradients), the surface-driven $K$-profile is restricted to below cloud base and the mass flux convection scheme is triggered from that level. Mixing across the top of the boundary layer is through an explicit entrainment parametrization that is coupled to the radiative fluxes and the dynamics through a sub-grid inversion diagnosis. If the thermodynamic conditions are right, cumulus penetration into a stratocumulus layer can generate additional turbulence and cloud-top entrainment in the stratocumulus by enhancing evaporative cooling at cloud-top. There are additional non-local fluxes of heat and momentum in order to generate more vertically uniform potential temperature and wind profiles in convective boundary layers. For stable boundary layers and in the free troposphere a local Richardson number scheme (Smith, 1990 ) is used with the stable stability dependence given over the sea by the "sharp" function and over land by the "MEStail" function (which matches linearly between an enhanced mixing function at the surface and "sharp" at $200 \mathrm{~m}$ and above). This additional near-surface mixing is motivated by the effects of surface heterogeneity, such as those described in McCabe and Brown (2007). The resulting diffusion equation is solved implicitly using the monotonicallydamping, second-order-accurate, unconditionally-stable numerical scheme of Wood et al. (2007). The kinetic energy dissipated through the turbulent shear stresses is returned to the atmosphere as a local heating term.

\subsection{Convection}

The convection scheme represents the sub-grid scale transport of heat, moisture and momentum associated with cumulus clouds within a grid-box. The MetUM uses a mass flux convection scheme based on Gregory and Rowntree (1990) with various extensions to include down-draughts (Gregory and Allen, 1991) and convective momentum transport (CMT). The current scheme consists of three stages: (i) convective diagnosis to determine whether convection is possible from the boundary layer; (ii) a call to the shallow or deep convection scheme for all points diagnosed deep or shallow by the first step; (iii) a call to the mid-level convection scheme for all grid-points.

The convective diagnosis is based on an undilute parcel ascent from the near surface for grid-boxes where the surface layer is unstable and forms part of the boundary layer diagnosis (Lock et al., 2000). Shallow convection is diagnosed if the following conditions are met: (i) the parcel attains neutral buoyancy below $2.5 \mathrm{~km}$ or below the freezing level whichever is higher; (ii) the air in model levels forming a layer of order $1500 \mathrm{~m}$ above this has a mean vertical velocity less than $0.02 \mathrm{~m} \mathrm{~s}^{-1}$. Otherwise, convection diagnosed from the boundary layer is defined as deep.
The deep convection scheme differs from the original Gregory and Rowntree (1990) scheme in using a convective available potential energy (CAPE) closure based on Fritsch and Chappell (1980). Mixing detrainment rates now depend on relative humidity and forced detrainment rates adapt to the buoyancy of the convective plume (Derbyshire et al., 2011). The CMT scheme uses a flux gradient approach (Stratton et al., 2009).

The shallow convection scheme uses a closure based on Grant (2001) and has larger entrainment rates than the deep scheme consistent with cloud resolving model (CRM) simulations of shallow convection. The shallow CMT uses flux-gradient relationships derived from CRM simulations of shallow convection (Grant and Brown, 1999).

The mid-level scheme operates on any instabilities found in a column above the top of deep or shallow convection or above the lifting condensation level. The scheme is largely unchanged from Gregory and Rowntree (1990), but uses the Gregory et al. (1997) CMT scheme and a CAPE closure. The mid-level scheme operates mainly either overnight over land when convection from the stable boundary layer is no longer possible or in the region of mid-latitude storms. Other cases of mid-level convection tend to remove instabilities over a few levels and do not produce much precipitation.

The timescale for the CAPE closure, which is used for the deep and mid-level convection schemes, is essentially fixed at a chosen value; however, if extremely high large scale vertical velocities are detected in the column then the timescale is rapidly reduced to ensure numerical stability. The choice of timescale for the CAPE closure depends on a pragmatic balance between model stability and model performance. In practice, this means that the timescale is currently dependent on the horizontal resolution and hence it falls outside the definition of GA3.0.

\subsection{Structure of the atmospheric model timestep}

The order of the physical parametrizations described above within the model timestep and their coupling to the atmospheric model's dynamics can be considered part of the design of the dynamical core. This requires a considered balance between stability, computational cost and both physical and numerical accuracy. The MetUM's timestepping treats slow timescale processes in parallel prior to the main advection step. This is followed by the fast timescale processes, which are treated sequentially, prior to the final dynamical solution (Staniforth et al., 2002). In this framework, the slow processes include radiation, large scale precipitation and gravity wave drag, whilst the fast processes include atmospheric (boundary layer) turbulence, convection and coupling to the land surface model. Prognostic cloud variables and tracers such as aerosols are advected by the semi-Lagrangian dynamics. Their sources and sinks occur where appropriate within the physical parametrization schemes (e.g. phase changes in the microphysics, wash-out 
in large scale precipitation and mixing in the boundary layer and turbulence schemes). Chemical and physical process internal to the aerosol scheme occur at the end of the timestep.

\subsection{Atmospheric aerosols and chemistry}

As discussed in Sect. 2, the modelling of atmospheric aerosols and chemistry is considered as a separate component of the full Earth System and remains outside the scope of this document. The impact of aerosols on atmospheric parametrizations, however, is part of the Global Atmosphere component and has therefore been included in the descriptions above. The treatment of tropospheric aerosols in systems which do not model these explicitly is supplemented by the use of a three-dimensional monthly climatology for each aerosol species, although currently these are only used to model the direct aerosol effect. In addition to the treatment of these tropospheric aerosols, GA3.0 includes a simple stratospheric aerosol climatology based on Cusack et al. (1998); it also includes the production of stratospheric water vapour via a simple methane oxidation parametrization (Untch and Simmons, 1999).

\subsection{Land surface and hydrology: Global Land 3.0}

The exchange of fluxes between the land surface and the atmosphere is an important mechanism for heating and moistening the atmospheric boundary layer. In addition, the exchange of $\mathrm{CO}_{2}$ and other greenhouse gases plays a significant role in understanding future climate change. The hydrological state of the land surface contributes to impacts such as flooding and drought as well as providing fresh water fluxes to the ocean, which influences ocean circulation. Therefore, a land surface model needs to be able to represent this wide range of processes over all surface types that are present on the Earth.

GL3.0 uses a new community land surface model, JULES (Joint UK Land Environment Simulator Best et al., 2011; Clark et al., 2011), to model all of the processes at the land surface and in the sub-surface soil. JULES is based on a combination of the Met Office Surface Exchange Scheme (MOSES, Cox et al., 1999) and the TRIFFID (Top-down Representation of Interactive Foliage and Flora Including Dynamics) dynamic vegetation model (Cox et al., 2000; Cox, 2001). A tile approach is used to represent sub-grid scale heterogeneity (Essery et al., 2003), with the surface of each land point subdivided into five types of vegetation (broadleaf trees, needleleaf trees, temperate $\mathrm{C} 3$ grass, tropical $\mathrm{C} 4$ grass and shrubs) and four non-vegetated surface types (urban areas, inland water, bare soil and land ice).

Vegetation canopies are represented in the surface energy balance through the coupling to the underlying soil. This canopy is coupled via radiative and turbulent exchange, whilst any bare soil component couples through conduction. JULES also uses a canopy radiation scheme to represent the penetration of light within the vegetation canopy and its subsequent impact on photosynthesis (Mercado et al., 2007). In addition, the canopy can interact with snow, with some of the snow intercepted by the canopy itself and the remainder being held under the canopy. This impacts on the surface albedo, the snow sublimation and the snow melt. The vegetation canopy code has been adapted for use with the urban surface type by defining an "urban canopy" with the thermal properties of concrete (Best, 2005). This has been demonstrated to give improvements over representing an urban area as a rough bare soil surface. Similarly, this canopy approach has also been adopted for the representation of lakes. The original representation in MOSES was through a soil surface that could evaporate at the potential rate (i.e. a soggy soil), which can been shown to have incorrect seasonal and diurnal cycles for the surface temperature. By defining an "inland water canopy" and setting the thermal characteristics to those of a suitable depth of water (taken to be $1 \mathrm{~m}$ ), a better diurnal cycle for the surface temperature is achieved. For Earth System modelling JULES includes soil carbon, comprising of four carbon pools, which is based on the RothC soil carbon scheme (Jenkinson et al., 1990; Coleman and Jenkinson, 1999). Also included are interactive methane emissions from wetland areas (Gedney et al., 2004).

Surface fluxes are calculated separately on each tile using surface similarity theory. In stable conditions the similarity functions of Beljaars and Holtslag (1991) are adopted, whilst in unstable conditions the functions are taken from Dyer and Hicks (1970). The effects on surface exchange of both boundary layer gustiness (Godfrey and Beljaars, 1991) and deep convective gustiness (Redelsperger et al., 2000) are included. $1.5 \mathrm{~m}$ temperatures and $10 \mathrm{~m}$ winds are interpolated between the model's grid-levels using the same similarity functions, but a parametrization of transitional decoupling in very light winds is included in the calculation of the $1.5 \mathrm{~m}$ temperature.

Soil processes are represented using a 4 layer scheme for the heat and water fluxes with hydraulic relationships taken from van Genuchten (1980). As in MOSES, these four soil layers have thicknesses from the top down of $0.1,0.25,0.65$ and $2.0 \mathrm{~m}$. The impact of moisture on the thermal characteristics of the soil is represented using a simplification of Johansen (1975), as described in Dharssi et al. (2009). The energetics of water movement within the soil is taken into account, as is the latent heat exchange resulting from the phase change of soil water from liquid to solid states. Sub-grid scale heterogeneity of soil moisture is represented using the Large Scale Hydrology approach (Gedney and Cox, 2003), which is based on the topography based rainfall-runoff model TOPMODEL (Beven and Kirkby, 1979). This enables the representation of an interactive water table within the soil that can be used to represent wetland areas, as well as increasing surface runoff through heterogeneity in soil moisture driven by topography. 
A river routing scheme is used to route the total runoff from inland grid-points both out to the sea and to inland basins, where it can flow back into the soil moisture. Excess water in inland basins is distributed evenly across all sea outflow points. In coupled model simulations the resulting freshwater outflow is passed to the ocean, where it is an important component of the thermohaline circulation, whilst in atmosphere/land-only simulations this ocean outflow is purely diagnostic. River routing calculations are performed using the TRIP (Total Runoff Integrating Pathways) model (Oki and Sud, 1998), which uses a simple advection method (Oki, 1997) to route total runoff along prescribed river channels on a $1 \times 1^{\circ}$ grid using a $3 \mathrm{~h}$ timestep. Land surface runoff accumulated over this timestep is mapped onto the river routing grid prior to the TRIP calculations, after which soil moisture increments and total outflow at river mouths are mapped back to the atmospheric grid (Falloon and Betts, 2006). This river routing model is not currently being used in limited area or NWP implementations of GA3.0/GL3.0.

\section{Developments since Global Atmosphere/Land 2.0}

In this section, we describe in more detail some of the major developments in the Global Atmosphere and Global Land configurations since GA2.0/GL2.0 (Arribas et al., 2011).

\subsection{Solar and terrestrial radiation}

In GA3.0, the treatment of ozone absorption in the ultraviolet has been upgraded based on Zhong et al. (2008). The first SW band is divided into six sub-bands each of which has one ozone absorption coefficient. This allows the solar irradiance to be specified for each sub-band facilitating climate experiments which use a varying solar spectral irradiance. The total number of $k$-terms has increased from 20 in GA2.0 to 21 for the major gases in the SW bands.

The solar spectrum has been upgraded from the Kurucz and Bell (1995) spectrum used in GA2.0. Below $735 \mathrm{~nm}$, the new spectrum is based on satellite observations meaned over the two solar cycles between 1983 and 2004 inclusive (data updated from Lean, 2000). Above $735 \mathrm{~nm}$ the Kurucz spectrum is retained. The new spectrum significantly reduces a warm bias that is present in the stratosphere in GA2.0.

A treatment of cloud inhomogeneity has been introduced as described in Hill et al. (2011). A stochastic cloud generator based on Räisänen et al. (2004) is used to generate 64 cloud profiles to represent each sub-grid field. This assumes the horizontal variation in the in-cloud water content follows a Gamma distribution with a fractional standard deviation of 0.75 . Vertical overlap of the sub-grid cloud assumes "exponential-random-overlap" (Hogan and Illingworth, 2000) with a decorrelation scale of $100 \mathrm{hPa}$ for the cloud fraction and $50 \mathrm{hPa}$ for the condensate. The sub-grid cloud field is then sampled using the Monte Carlo Indepen-

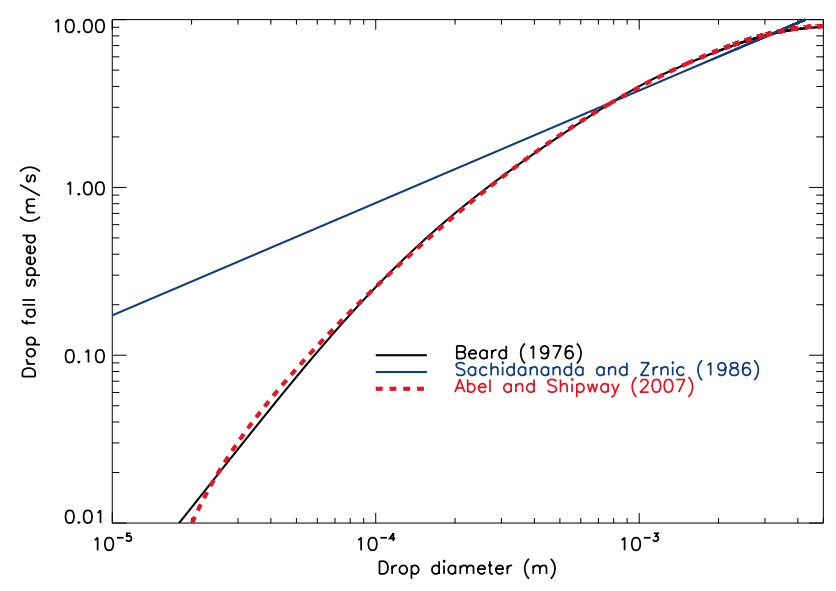

Fig. 1. Raindrop fall speed relations as a function of diameter. The blue line shows the fall speed relation of Sachidananda and Zrnić (1986), which was used in GA2.0 and before. The black line is the observations of Beard (1976) and the red line is the new parametrization of Abel and Shipway (2007).

dent Column Approximation (Pincus et al., 2003) which uses a different sub-grid cloud profile for each monochromatic radiative transfer calculation. For spectral regions with low gaseous absorption, where the cloud radiative effect is greatest, extra cloud profiles are sampled in order to reduce random noise. The number of monochromatic calculations are increased by 6 in the LW and 10 in the SW using the method of optimal sampling described in Hill et al. (2011). Inclusion of the radiative effects of cloud inhomogeneity corrects a long-standing bias in the transmissivity of grid-box mean cloud, and has an impact on the top-of-atmosphere radiation balance.

\subsection{Large scale precipitation}

GA3.0 includes a number of modifications to the microphysics scheme, which were introduced to reduce the spurious occurrence of drizzle that has been made worse by the introduction of the PC2 cloud scheme (Wilson et al., 2008a). The rain fall speeds have been modified from the simple power-law relation described by Sachidananda and Zrnić (1986) to a more complex relation of Abel and Shipway (2007)

$V_{\mathrm{R}}(D)=c_{1 \mathrm{R}} D^{d_{\mathrm{R}}} e^{-h_{1 \mathrm{R}} D}+c_{2 \mathrm{R}} D^{d_{2 \mathrm{R}}} e^{-h_{2 \mathrm{R}} D}$,

where $V_{\mathrm{R}}$ is the raindrop fall speed, $D$ is its diameter and the constants $c_{1 \mathrm{R}}=4845.1 \mathrm{~m}^{\left(1-d_{1 \mathrm{R}}\right)} \mathrm{s}^{-1}, d_{1 \mathrm{R}}=1.0, h_{1 \mathrm{R}}=$ $195.0 \mathrm{~m}^{-1}, c_{2 \mathrm{R}}=-446.009 \mathrm{~m}^{\left(1-d_{2 \mathrm{R}}\right)} \mathrm{s}^{-1}, d_{2 \mathrm{R}}=0.782127$ and $h_{2 \mathrm{R}}=4085.35 \mathrm{~m}^{-1}$. Figure 1 shows the fall speed as a function of raindrop diameter for the Abel and Shipway (2007) parametrization, the observations of Beard (1976) and the GA2.0 fall speed relation of Sachidananda and Zrnić (1986). It can be seen that the Abel and Shipway (2007) 
relation provides a closer fit to the Beard (1976) observations than the Sachidananda and Zrnić (1986) relation. For drizzle-sized drops of a few microns, the Sachidananda and Zrnić (1986) fall speed is up to a factor of ten too high. Using Abel and Shipway (2007) means that we can allow drizzle to fall more slowly and evaporate more readily in the sub-cloud layer. In addition, the accretion rate given by Wilson and Ballard (1999) has a fall velocity component; by allowing a slower fall velocity for smaller drizzle drops in the cloud, the accretion rates are much lower and less drizzle will fall out of the cloud base.

The diagnostic rain scheme used in Wilson and Ballard (1999) and the GA2.0 configuration makes the assumption that all rain will fall out of the column in one timestep. However, drizzle drops falling at the order of $10 \mathrm{~cm} \mathrm{~s}^{-1}$ or less from a cloud base at around $500 \mathrm{~m}$ altitude will take over $5000 \mathrm{~s}$ to reach the surface, which is longer than the timesteps used by the systems that follow GA3.0. Thus the diagnostic rain assumption is not valid. Furthermore, as it is not possible for the diagnostic rain assumption to hold rain in the column between timesteps, we have progressed to using a prognostic rain formulation. This has been used operationally in convection permitting configurations of the MetUM for some time and has been described in detail by Lean (2002), who found that in high-resolution simulations, the location of rainfall in the vicinity of orography agreed much better with observations when using a prognostic scheme. For a more accurate representation of drizzle processes, Posselt and Lohmann (2008) show that it is necessary to include a number of sub-timesteps of the microphysics scheme and they suggested using 30 sub-timesteps with a 15 min model timestep (i.e. one sub-timestep for each $30 \mathrm{~s}$ of the model timestep). However, in our experiments, we find that using one sub-timestep for every $2 \mathrm{~min}$ of the timestep provides very similar results to using more iterations, yet without the additional computational cost.

\subsection{Convection}

At GA3.0 two of the conditions for the diagnosis of shallow convection were relaxed, in particular: (i) the requirement that an inversion was detected above the level of neutral buoyancy was removed, and (ii) the maximum large scale vertical velocity allowed above the level of neutral buoyancy was increased from $0.0 \mathrm{~m} \mathrm{~s}^{-1}$ to $0.02 \mathrm{~m} \mathrm{~s}^{-1}$. These changes effectively make the conditions for the diagnosis of deep convection more stringent. They were made to prevent the spurious diagnosis of deep convection in situations where the deep convection scheme was not designed to operate.

\subsection{Land surface and hydrology}

In the Global Land configuration, the major change with GL3.0 is the replacement of the MOSES-II (Essery et al., 2003) model with JULES (Best et al., 2011; Clark et al.,
2011). For this initial implementation, JULES has been configured to have as few scientific differences from the MOSES-II model used in GL2.0 as possible. The main residual difference is in the linearisation assumptions used for the surface energy balance. In MOSES, the terms are linearised around the top soil layer temperature, whilst in JULES they are linearised around the previous timestep value of the surface temperature. The more accurate linearisation of this term in the energy balance in JULES leads to increased outgoing longwave radiation from the surface and hence a slight surface cooling. The most significant advantage of implementing JULES, however, is that its additional functionality and flexibility will allow major new developments in the Global Land configuration in the coming years. For instance, JULES currently consists of options for new snow and urban schemes, whilst new modules for plant and soil nitrogen, crops and an alternative dynamic vegetation scheme are being developed.

In coupled systems, GL3.0 introduces the facility to read in an iceberg calving ancillary, which is calibrated from a previous model run. This allows a flux of freshwater and associated latent heat to be added to the total flux over the ocean with a spatial extent representing the calving of icebergs from glaciers. This has no impact in atmosphere/landonly systems but, in the absence of a full treatment of land ice processes, such a term allows ocean models coupled to GA3.0/GL3.0 to remain in freshwater balance.

\section{Global Atmosphere 3.1 and Global Land 3.1}

GA3.0 and GL3.0 are the Met Office's first attempt at defining a coupled global atmosphere/land configuration that can be used across all timescales. During their development, a number of differences between the global model configurations used in the operational NWP suite and the latest climate configurations were removed, ranging from small changes in individual parameters to the introduction of new parametrizations. For a small number of these differences, the operational NWP suite had not previously been brought into line with climate configurations, despite knowledge that their parametrizations had a more sound physical basis, because these changes had small but detrimental impacts on NWP performance. In order to maximise the possibility of implementing a Global Atmosphere based configuration in the operational NWP suite, therefore, we took the conservative approach of re-introducing a small number of these differences by defining the branch configurations Global Atmosphere 3.1 (GA3.1) and Global Land 3.1 (GL3.1); these branch configurations were tested for inclusion in the NWP suite ahead of GA3.0/GL3.0. Global NWP tests of GA3.0/GL3.0 do show reasonable performance, but lead to a small reduction in forecast skill for several important parameters. Whilst the operational implementation of GA3.1/GL3.1 means that we have not yet adopted a truly seamless forecast system, it will 
allow us time to understand why this performs better than GA3.0/GL3.0 at short forecast ranges; we aim to remove as many of these differences as possible during the development of GA4.0/GL4.0. Finally, the development process itself relies on using GA3.0/GL3.0 and not GA3.1/GL3.1 as its future baseline; this will stop the introduction of additional compensating errors that make it harder to move away from the settings in the branch configurations.

The primary differences between GA3.1 and GA3.0 are in the radiation and boundary layer schemes, whilst GL3.1 and GL3.0 differ most significantly in their treatment of the land surface tiles and the runoff of precipitation from the soil. Each of these differences is described in detail below.

\subsection{Solar and terrestrial radiation}

With a focus on computational speed and improved tropospheric heating rates, GA3.1 does not include the enhanced treatment of $\mathrm{CO}_{2}$ and $\mathrm{O}_{3} \mathrm{LW}$ absorption (Zhong and Haigh, 2000). This reduces the number of $k$-terms from 47 to 33 for the major gases in the LW bands, with a similar reduction in the computation time. The optical properties of ammonium nitrate are included as a "delta" aerosol climatology to represent a missing process left by the other aerosol climatologies when compared to observations.

\subsection{Atmospheric boundary layer}

As discussed in Brown et al. (2008), the Met Office's global NWP model has for many years used stable stability functions, together with adjustments to the mixing lengths, that combine to give significantly more mixing than the GA3.0 setup and this remains as a difference in GA3.1. This is, in fact, common practice in many NWP centres and typically has been found to reduce spurious cooling at the surface and increase skill in predicting the synoptic evolution (Viterbo et al., 1999; Beljaars and Viterbo, 1998). Although the argument can be made that these functions are parametrizing the effects of heterogeneity, studies suggest this enhancement is excessive (e.g. see discussion in McCabe and Brown, 2007) and that they may simply be compensating for errors elsewhere in the surface energy balance.

\subsection{Convection}

Unlike GA3.0, GA3.1 uses a CAPE closure timescale that is independent of horizontal resolution and which is set to $30 \mathrm{~min}$. All other convection options are identical between GA3.0 and GA3.1.

\subsection{Land surface and hydrology: Global Land 3.1}

The most significant difference between GL3.1 and GL3.0 is that GL3.1 does not perform its land surface calculations on each of the 9 surface tiles separately, but amalgamates the properties of each surface type weighted by their gridbox fraction into a single tile. As well as being only an approximation of a truly tiled surface, this choice means that
GL3.1 is not able to hold separate snow stores above and below the tree canopy. To compensate for this, GL3.1 uses a snow-covered albedo for trees of 0.15 , rather than the 0.25 used in GL3.0. The amalgamated tile approach also means that in GL3.1 we cannot introduce an "inland water canopy" to mimic the increased thermal capacity of deep lakes. The other land surface differences are that GL3.1 uses a bare soil roughness length of $3.2 \mathrm{~mm}$ and a sea-ice roughness length of $100 \mathrm{~mm}$ for marginal ice zones and $3 \mathrm{~mm}$ for pack ice. In GL3.0 these values are $0.3 \mathrm{~mm}, 0.5 \mathrm{~mm}$ and $0.5 \mathrm{~mm}$, respectively. GL3.1 does not use the Large Scale Hydrology approach to calculate its surface and sub-surface runoff, and therefore has no representation of sub-grid heterogeneity in this process.

\section{Preliminary model evaluation}

An important part of the MetUM Global Atmosphere development process is its evaluation across a variety of resolutions and timescales. The principle of this evaluation follows that previously used for assessing the performance of the Met Office's climate and NWP models in which the the model is assessed using a relatively large basket of quantitative measures, which are collated and investigated qualitatively. At the time of writing, the evaluation of the GA3.0/GL3.0 configurations in a large subset of the systems listed in Sect. 2.1 is underway. A full assessment of the performance of GA3.0/GL3.0 is beyond the scope of this paper. In this section, however, we present a small set of results from some of the evaluation simulations that have already completed.

\subsection{N96 HadGEM3 30 yr AMIP climate simulation}

Because this is only the first in a planned series of papers, there are no results yet published from an equivalent assessment of GA2.0/GL2.0. Instead, we present a comparison of GA3.0/GL3.0 in a $30 \mathrm{yr}$ atmosphere/land-only climate integration at N96 resolution (approximately $135 \mathrm{~km}$ in the mid-latitudes) with an equivalent N96 simulation of HadGEM2-A (HadGEM2 Development Team: Martin et al., 2011). Both GA3.0/GL3.0 and HadGEM2-A simulations use the same sea surface temperatures, sea ice fractions, $\mathrm{CO}_{2}$ concentrations and other external forcings as the Atmospheric Model Intercomparison Project (AMIP) framework of the Coupled Model Intercomparison Project phase 5 (CMIP5, Taylor et al., 2009). Both simulations cover the period from 1979 to 2008.

The overall assessment of the global tropospheric circulation requires a comparison of the model's mean flow and modes of variability against a collection of trusted observational climatologies. A concise way of presenting these results is through a set of normalised assessment criteria, each of which are calculated as the root mean square error of a meaned field in GA3.0/GL3.0 divided by the root mean 


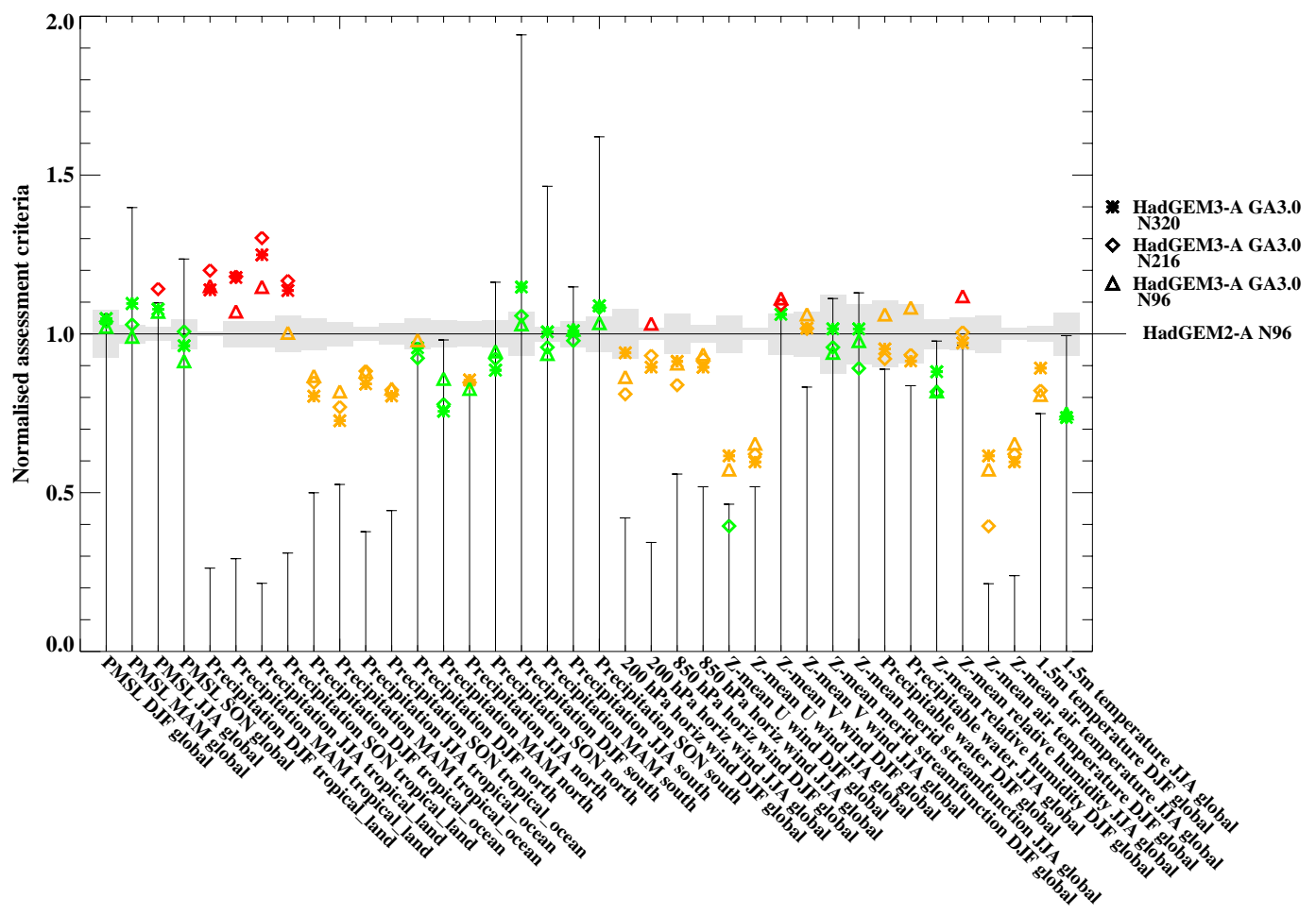

Fig. 2. Normalised assessment criteria (ratios of mean field root mean square errors) for a range of atmospheric fields from GA3.0/GL3.0 HadGEM3-A simulations across a range of resolutions compared to an N96 HadGEM2-A baseline. Statistics shown are from the seasons December to February (DJF), March to May (MAM), June to August (JJA) and September to November (SON) and for regions global, tropical land (land points between $30^{\circ} \mathrm{N}$ and $30^{\circ} \mathrm{S}$ ), tropical ocean (ocean points between $30^{\circ} \mathrm{N}$ and $30^{\circ} \mathrm{S}$ ), north $\left(30^{\circ}-90^{\circ} \mathrm{N}\right)$ and south $\left(30^{\circ}-90^{\circ} \mathrm{S}\right)$. The observation datasets used are HadSLP2 pressure at mean sea level (Allan and Ansell, 2006), GPCP precipitation (Adler et al., 2003), SSMI precipitable water (Wentz and Spencer, 1998) and CRUTEM3 $1.5 \mathrm{~m}$ temperature (Brohan et al., 2006), whilst the remaining climatologies are from ERA-interim reanalyses (Berrisford et al., 2009). The whisker bars are observational uncertainty, which is calculated by comparing these with alternative datasets; these are ERA-40 pressure at mean sea level and precipitable water (Uppala et al., 2005), CMAP precipitation (Xie and Arkin, 1997), Legates and Willmott (1990) $1.5 \mathrm{~m}$ temperature and MERRA reanalyses for everything else (Bosilovich, 2008). The grey shading is the uncertainty associated with internal climate variability, which is estimated by comparing various $20 \mathrm{yr}$ segments of a long coupled simulation. The points represent simulations of GA3.0/GL3.0 at N96, N216 and N320 resolution, which ran for 30,30 and $20 \mathrm{yr}$, respectively.

square error of the same field in HadGEM2-A. The triangle symbols in Fig. 2 show the normalised assessment criteria from this N96 AMIP simulation for a range of atmospheric fields, namely: pressure at mean sea level, precipitation, horizontal winds at 200 and $850 \mathrm{hPa}$, precipitable water and screen-level temperature as well as zonal means of zonal and meridional winds, meridional streamfunction, temperature and relative humidity. Triangle symbols below the 1.0 line show fields that have improved relative to HadGEM2-A and symbols above this line show fields that are degraded. This figure shows that only 6 fields, dominated by tropical precipitation over land, are significantly worse than HadGEM2A (shown in red); 16 fields, however, are significantly better. The remaining fields either lie within model uncertainty (grey shading) or both models lie within observational uncertainty (whisker bars) where a clear improvement/detriment is hard to detect. Of these improved or neutral fields, 14 remain outside the range of uncertainty in the observations (orange) whilst 15 lie within this range (green). These results indicate that the performance of GA3.0/GL3.0 is a considerable improvement over that of HadGEM2-A; a similar analysis of top-of-atmosphere and surface radiation fluxes also shows a similar improvement.

The rest of this section will expand on some of the improvements and degradations highlighted in Fig. 2. Figure 3 illustrates a comparison of the screen-level $(1.5 \mathrm{~m})$ temperature from GA3.0/GL3.0 meaned over the season June-August (JJA) with that from HadGEM2-A and the CRUTEM3 observation dataset (Brohan et al., 2006). This and all following 4-up plots follow a standard layout in which panel (a) shows the mean field from the test, (b) the difference between the mean test and control, (c) the mean error in the control data and (d) the mean error in the test. Figure $3 \mathrm{c}$ shows that HadGEM2-A is excessively hot in North 

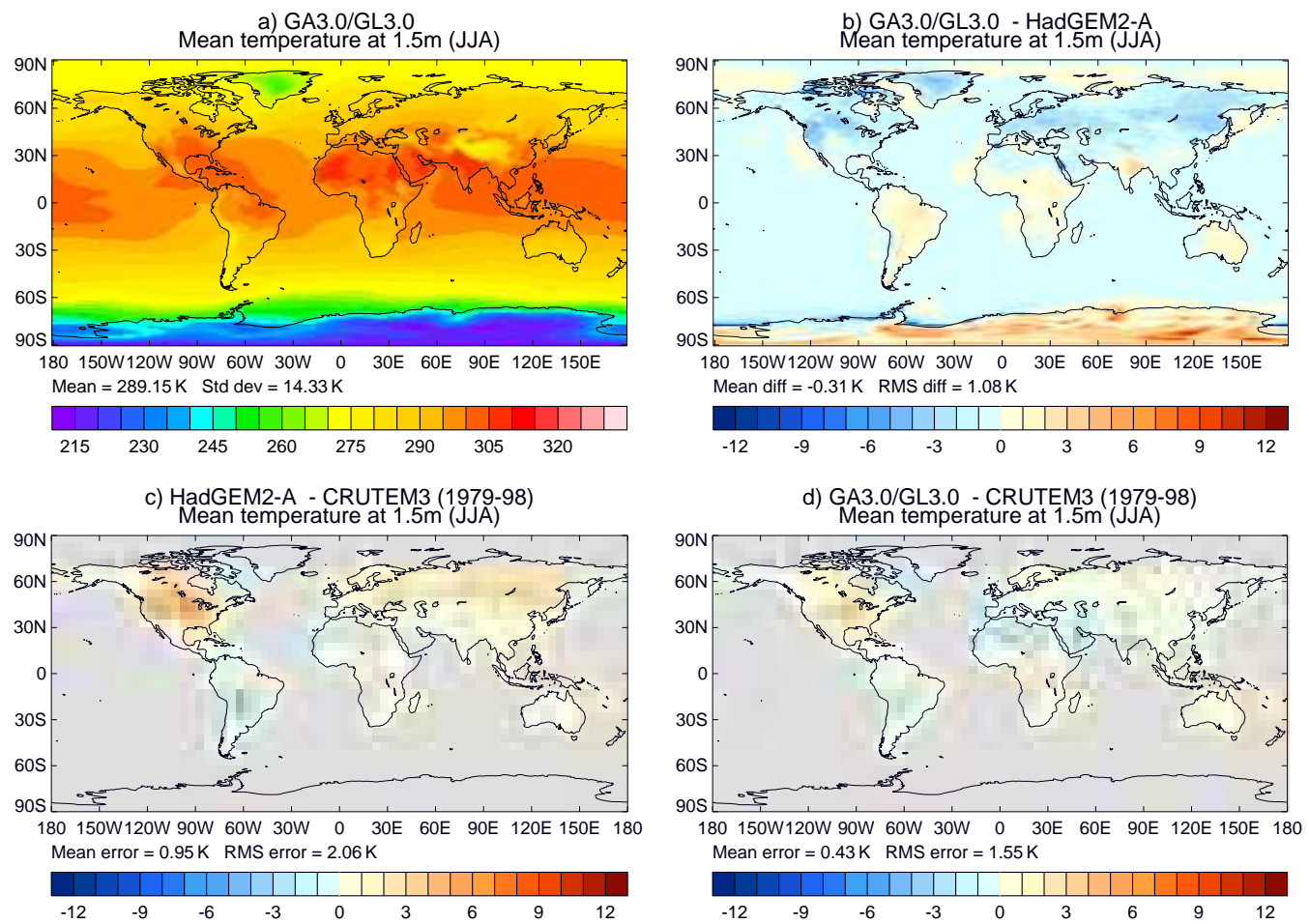

Fig. 3. Climatological $1.5 \mathrm{~m}$ temperatures during JJA in a $30 \mathrm{yr}$ N96 atmosphere/land-only simulation. (a) full field from GA3.0/GL3.0, (b) model difference (GA3.0/GL3.0 minus HadGEM2-A), (c) HadGEM2-A bias (HadGEM2-A minus observations) and (d) GA3.0/GL3.0 bias (GA3.0/GL3.0 minus observations). Observations used are from CRUTEM3 (Brohan et al., 2006).
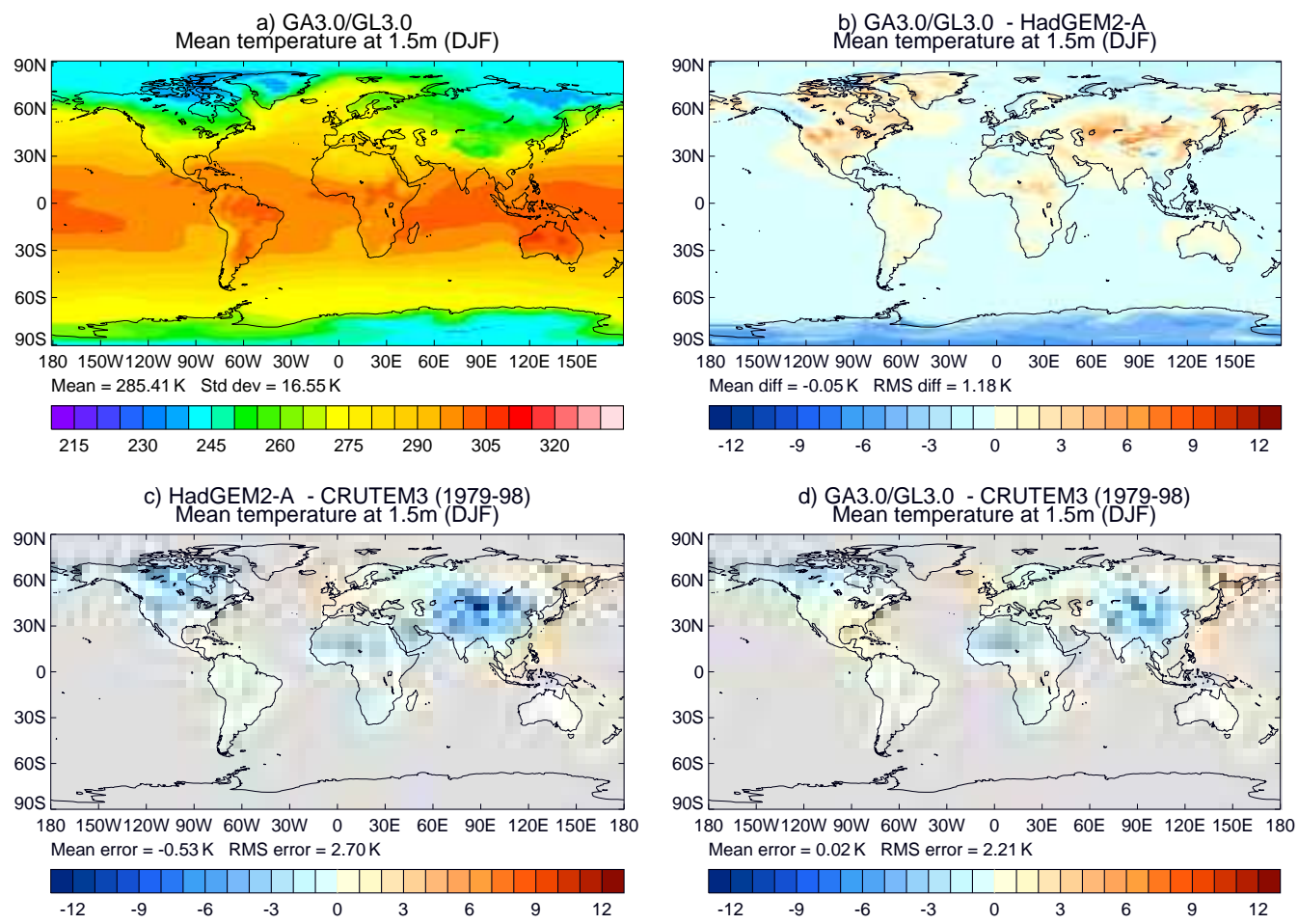

Fig. 4. Climatological $1.5 \mathrm{~m}$ temperatures during DJF in the $30 \mathrm{yr}$ N96 simulation using the same format as Fig. 3. 

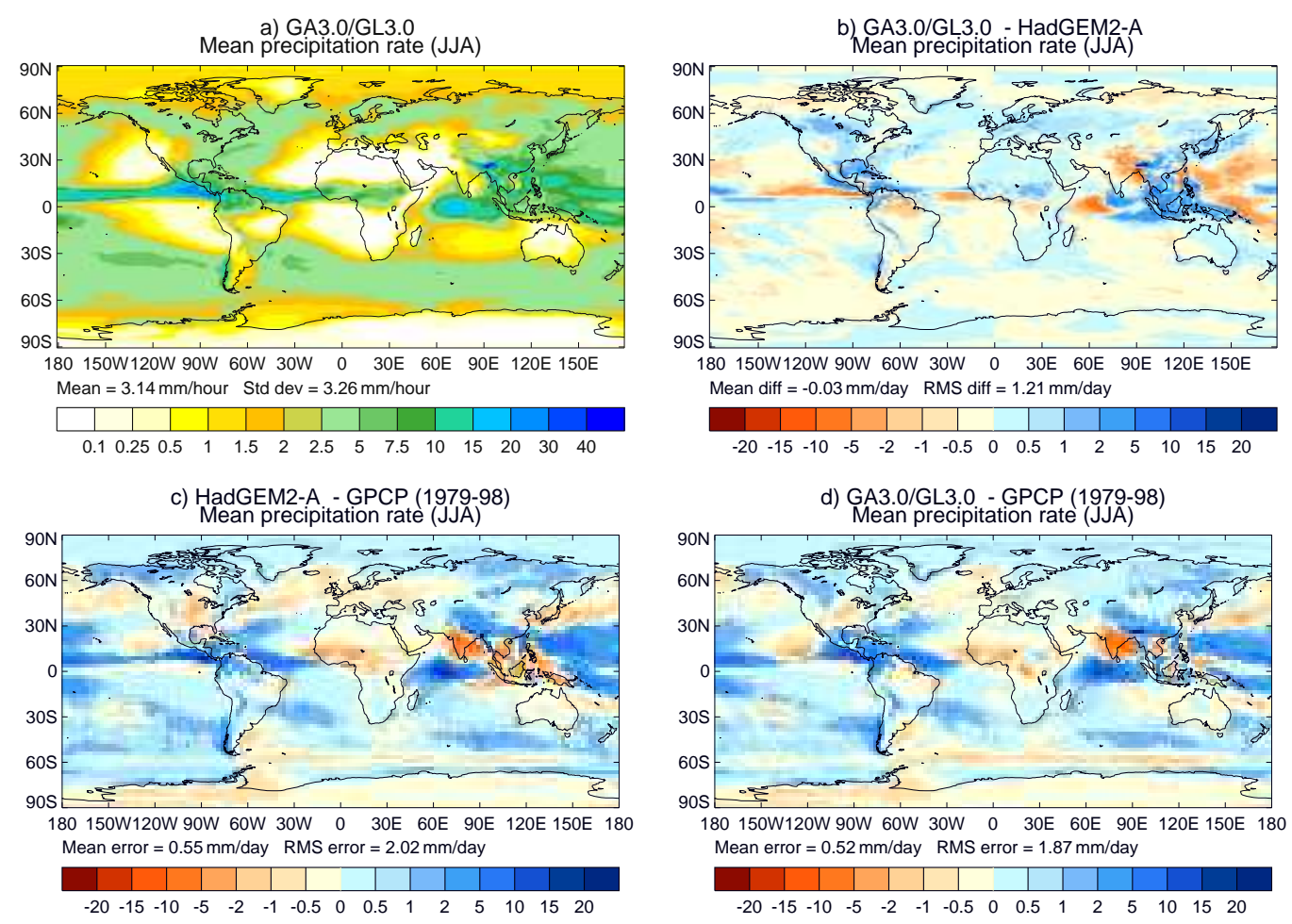

Fig. 5. Climatological precipitation during JJA in the $30 \mathrm{yr}$ N96 simulation using the same format as Fig. 3. Observations used are from GPCP (Adler et al., 2003).

America, Europe and Northern Asia. Figure 3b shows that the change in $1.5 \mathrm{~m}$ temperature between HadGEM2-A and GA3.0/GL3.0 has a spatial pattern that is approximately anticorrelated with the HadGEM2-A bias. This means that GA3.0/GL3.0 reduces these temperature biases leading to a new distribution of bias (Fig. 3d) in which the mean errors over Europe and northern Asia are close to zero and the bias over North America is significantly reduced. As each change to the model configuration since HadGEM2-A has been assessed in a $10 \mathrm{yr}$ N96 AMIP run, it is possible to suggest an attribution of some changes in performance to particular model enhancements. The physics change that appears to contribute most to these improvements in JJA temperatures is the use of van Genuchten soil hydraulics (van Genuchten, 1980) instead of those of Clapp and Hornberger (1978) and the replacement of soil properties derived from the International Geosphere-Biosphere Programme's Global Soil Data Task (Global Soil Data Task, 2000) with those derived from the Harmonised World Soil Database (Nachtergaele et al., 2008). This change allows the soil to retain more moisture near the surface, leading to increased latent heating and decreased surface temperatures. Figure 4 shows the equivalent plot for $1.5 \mathrm{~m}$ temperatures during December to February (DJF). In this season HadGEM2-A is excessively cold over North America and Central Asia. The GA3.0/GL3.0 simulation is warmer in these locations leading to reduced model biases. This improvement is partly due to improvements to soil thermal conductivity in the model (Dharssi et al., 2009). In GA3.0/GL3.0 the soil is more able to absorb heat within deep soil layers during the summer and gradually release that heat throughout the winter, warming the surface. Figure 5 shows model precipitation compared with Global Precipitation Climatology Project (GPCP) data (Adler et al., 2003) during JJA. In HadGEM2-A there are a range of model precipitation biases, including wet biases over the equatorial Indian Ocean and the Western Pacific, and dry biases over India, the Maritime Continent (Indonesia and surrounding islands) and the Sahel region of Africa. Most of these errors have reduced in GA3.0/GL3.0 with the exception of the dry bias over India. Despite the under-prediction of rain over India, we have seen an improvement in the Indian monsoon winds in GA3.0/GL3.0 (not shown). The dry bias over the Maritime Continent has been reduced mostly due to the inclusion of a "buddy" scheme for coastal gridpoints which uses an average wind speed over neighbouring sea points to split the level 1 wind speed into separate land and sea contributions. This enhances the wind speed over the sea part of the grid-box giving improved scalar fluxes there. The wet bias in the Western Pacific has also reduced in GA3.0/GL3.0. This is due to a range of convection parametrization changes including reducing the amount of convective momentum transport (Stratton et al., 2009) and 
increasing the timescale over which CAPE is removed by the convection scheme. The equatorial Indian Ocean and the Sahel region of Africa have also seen their biases reduce due to the use of the PC2 cloud scheme, which generates a net reduction in clouds and precipitation over the tropical oceans and a net increase in clouds and precipitation over tropical land. This increases precipitation over the Sahel (reducing the bias) and decreases precipitation over the equatorial Indian Ocean (also reducing the bias). Figure 6 shows the equivalent plot for precipitation during DJF. Many of the improvements seen in JJA are also seen in DJF including the increased precipitation over the Maritime Continent and the reduced precipitation over the western Pacific and equatorial Indian Ocean. One improvement that is specific to DJF occurs in the North Atlantic to the west of the UK where HadGEM2-A has a wet bias. GA3.0/GL3.0 has reduced the amount of precipitation in this region to such an extent that there is now a slight dry bias. There have been many physics changes introduced since HadGEM2-A that have affected the model's performance in the North Atlantic, which makes it difficult to attribute the cause of this change.

As stated earlier, many top-of-atmosphere radiation fields have improved between HadGEM2-A and GA3.0/GL3.0. Figure 7 shows the improvements in outgoing shortwave radiation during the DJF season (i.e. the amount of the Sun's radiation reflected out to space by clouds and the Earth's surface) compared to the Clouds and the Earth's Radiant Energy System (CERES) dataset (Wielicki et al., 1996). HadGEM2A reflects too much of the Sun's radiation in two small regions located to the west of Peru and to the west of Southern Africa; this is because it generates too much stratocumulus cloud in these regions and the thickness of this stratocumulus cloud is too uniform throughout the grid-box. These outgoing shortwave biases have been reduced in GA3.0/GL3.0 due to the following physics changes: (i) the PC2 cloud scheme, which represents different cloud régimes as a different balance between cloud creation and destruction processes; (ii) enhancing the turbulent entrainment mixing in stratocumulus over cumulus, which reduces the amount of stratocumulus cloud and outgoing shortwave and (iii) the McICA cloud inhomogeneity, which allows more shortwave radiation to pass through the thinner parts of the cloud, decreasing the amount of shortwave reflected back to space (Hill et al., 2011). We can see, however, a detrimental reduction in reflected solar radiation along the Intertropical Convergence Zone in the Pacific. Figure 7 also shows a negative bias in the Southern Ocean off the coast of Antarctica. This is associated with increased surface shortwave and leads to a Southern Ocean warming when GA3.0/GL3.0 are coupled to an ocean model (not shown). This bias is slightly reduced in GA3.0/GL3.0 due to prognostic rain with Abel and Shipway (2007) fall speeds allowing the slower droplets to evaporate more efficiently, which increases relative humidity and hence the cloud amount.

\subsection{Enhanced resolution AMIP climate simulations}

In addition to the $30 \mathrm{yr}$ N96 simulation discussed above, Fig. 2 shows the normalised assessment of a similar $30 \mathrm{yr}$ simulation at $\mathrm{N} 216$ resolution (approximately $60 \mathrm{~km}$ in the mid-latitudes) and a $20 \mathrm{yr}$ simulation (1979 to 1998) at N320 resolution (approximately $40 \mathrm{~km}$ in the mid-latitudes). This shows that in general, there are no widespread changes to the basic atmospheric state in response to the increased horizontal resolution when assessed against these low resolution climatologies. This is a reassuring confirmation that the performance of the GA3.0/GL3.0 configuration is traceable across this range of resolutions, which is a principle on which the MetUM Global Atmosphere development process relies. The increased resolution of these simulations, however, does enable the model to represent both regional and local climatology better, e.g. by improving precipitation distributions and amounts, especially near areas of orography. Enhanced resolution allows the more accurate modelling of extremes, including the number, intensity, and interannual variability of tropical cyclones, particularly in the Atlantic. Atmosphere/land-only simulations in other models have also shown stronger large scale motion and associated precipitation on the southern side of the Gulf Stream due to the atmosphere being able to react to strong SST gradients (Minobe et al., 2008). In previous simulations of coupled modelling systems, enhanced horizontal atmospheric resolution has been shown to lead to an improved El NiñoSouthern Oscillation (Shaffrey et al., 2009); it has also been seen to contribute to improvements in simulations of Atlantic blocking, again by being able to better respond to improved SSTs (Scaife et al., 2011). Figure 2 shows that at N216 and N320 we see an increase in the precipitation errors over tropical land compared to N96, although we have also seen an improvement to the rain deficit over India during JJA (not shown). There are also improvements in the precipitable water and relative humidity diagnostics. Looking at this in more detail, it can be seen in DJF and JJA zonal mean relative humidity plots (not shown) that the higher resolution models tend to increase the relative humidity through most of the troposphere in the tropics, and decrease it at mid to high latitudes, both of which are generally an improvement. This appears to be a robust result of increased resolution, as it is seen at both N320 and N216, and was also seen in comparing different resolution models during previous model assessments. The difference is most likely due to increased intensity of tropical deep convection in the higher resolution model, perhaps associated with a slight increase in the strength of the Hadley Circulation.

\subsection{Short-range NWP case studies}

Finally, we present some initial results from a comparison of GA3.0/GL3.0 and GA3.1/GL3.1 in a set of $20 \mathrm{NWP}$ case studies made up of 10 cases in the season December- 

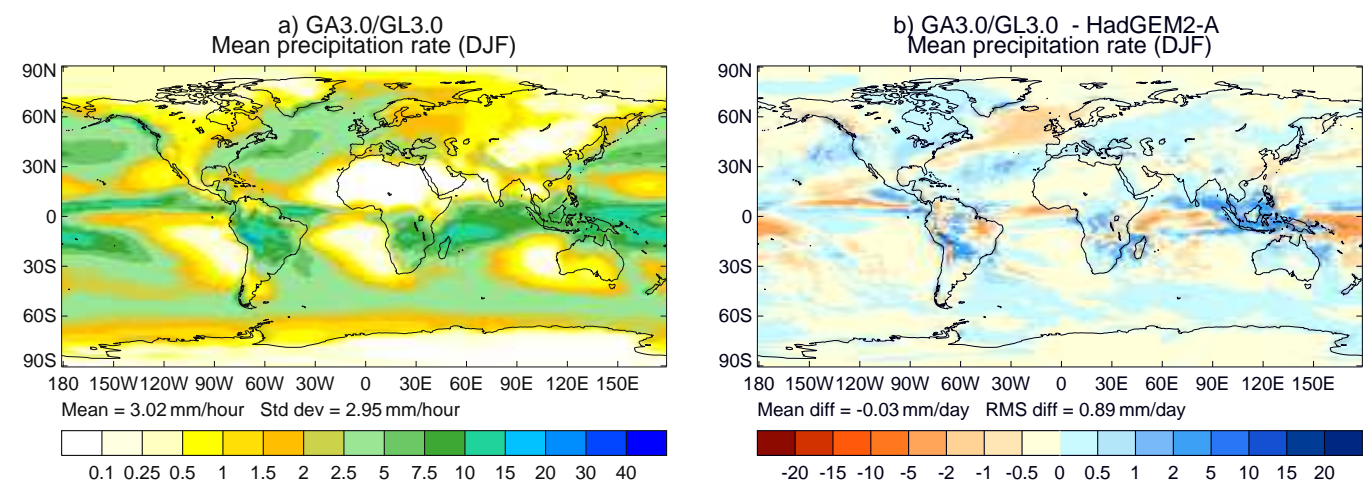

Mean diff $=-0.03 \mathrm{~mm} /$ day $\mathrm{RMS}$ diff $=0.89 \mathrm{~mm} /$ day

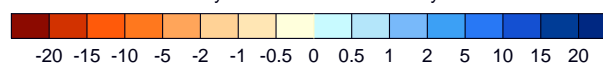

c) HadGEM2-A - GPCP (1979-98)

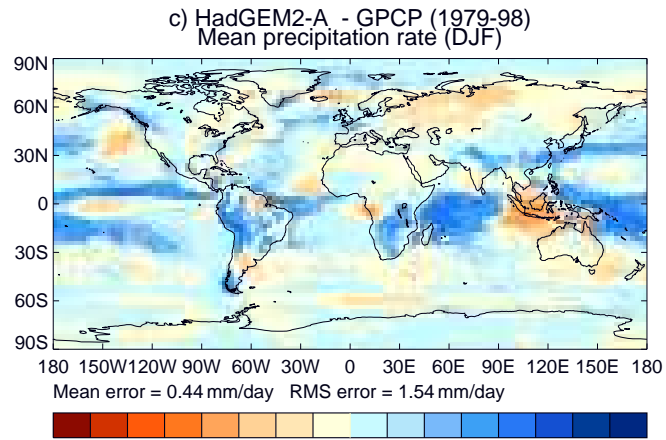

d) GA3.0/GL3.0 - GPCP (1979-98)
Mean precipitation rate (DJF)

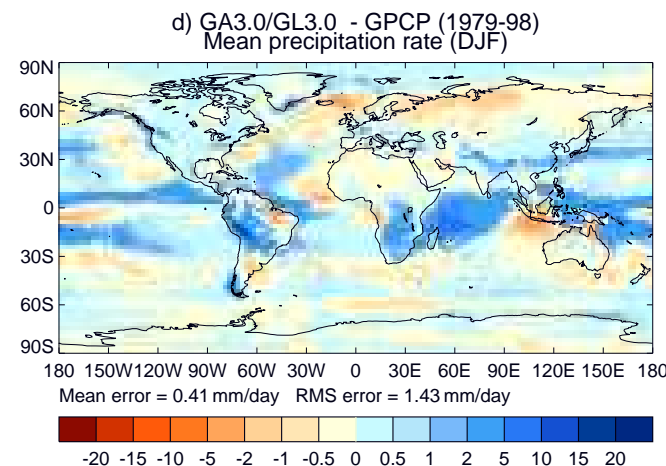

$\begin{array}{llllllllllllllll}-20 & -15 & -10 & -5 & -2 & -1 & -0.5 & 0 & 0.5 & 1 & 2 & 5 & 10 & 15 & 20\end{array}$

Fig. 6. Climatological precipitation during DJF in the $30 \mathrm{yr}$ N96 simulation using the same format as Fig. 3.
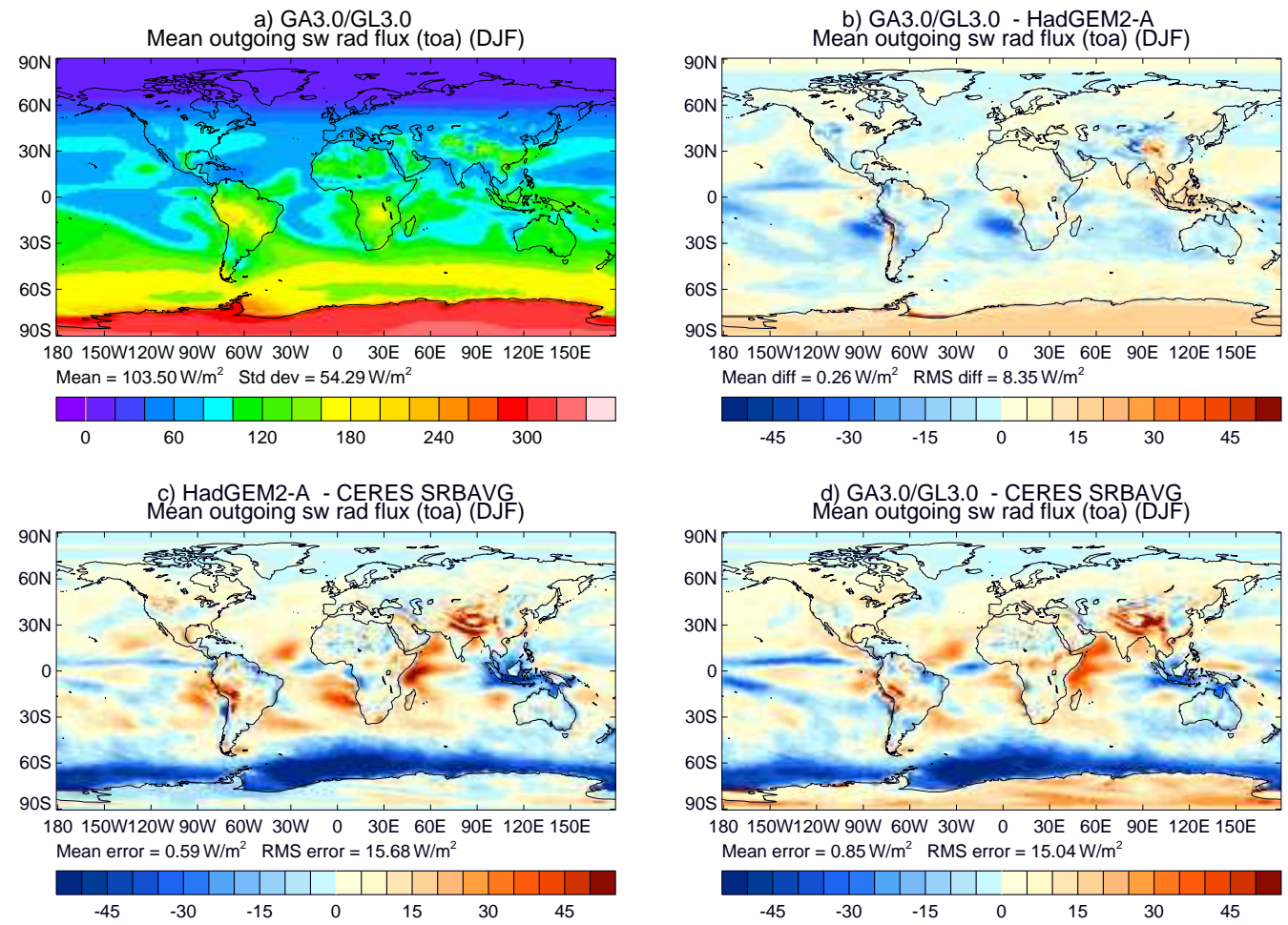

Fig. 7. Climatological outgoing shortwave radiation from the top of the atmosphere during DJF in the 30 yr N96 simulation using the same format as Fig. 3. Observations used are from CERES (Wielicki et al., 1996). 

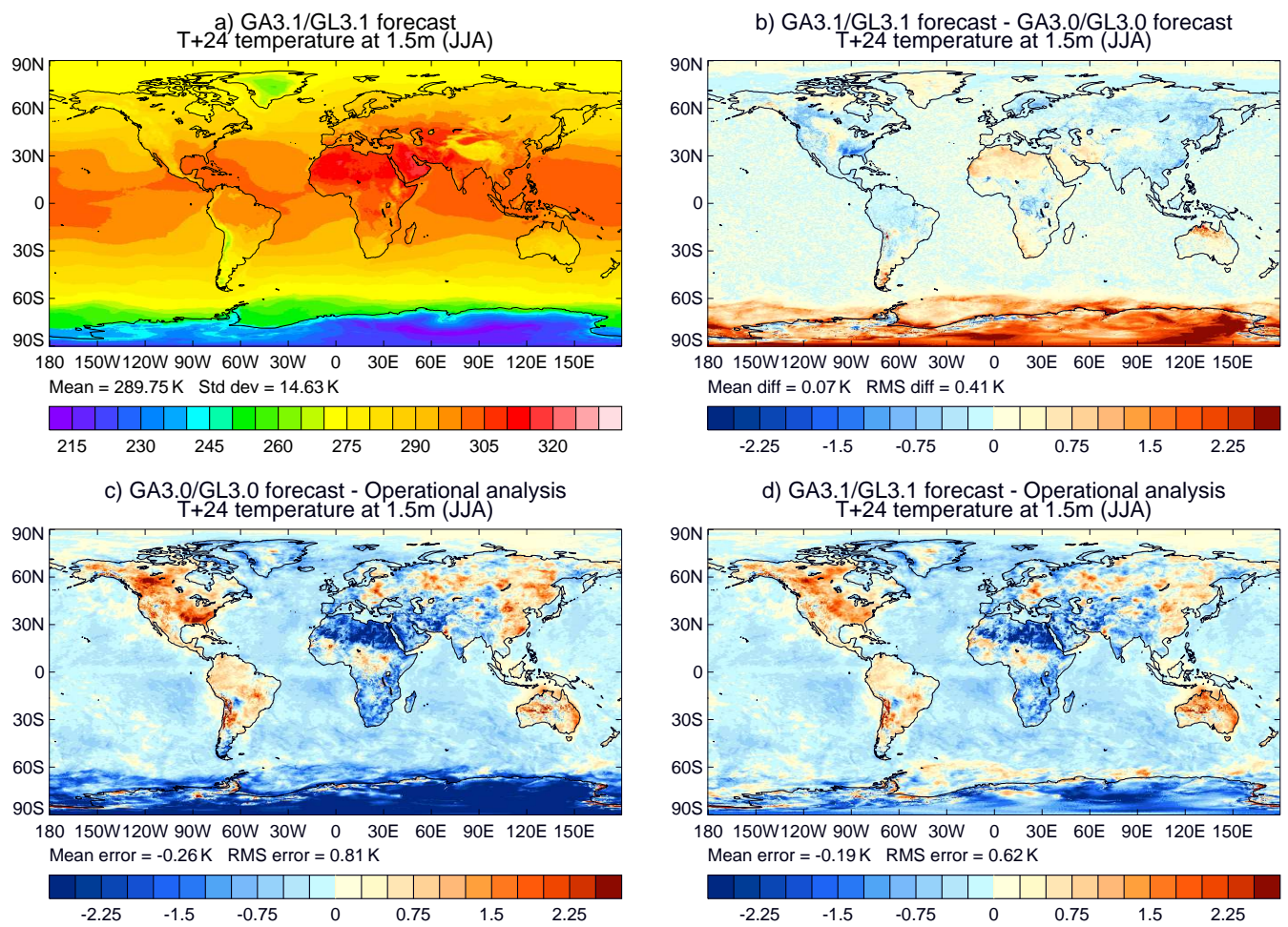

Fig. 8. Mean $24 \mathrm{~h}$ forecast $1.5 \mathrm{~m}$ temperatures during $10 \mathrm{~N} 320 \mathrm{NWP}$ case studies in JJA. (a) full field from GA3.1/GL3.1, (b) model difference (GA3.1/GL3.1 minus GA3.0/GL3.0), (c) GA3.0/GL3.0 bias (GA3.0/GL3.0 minus Met Office operational analyses) and (d) GA3.1/GL3.1 bias (GA3.1/GL3.1 minus analyses).

February (DJF) spread across DJF 2008/9 and 2009/10 and 10 cases in June-August (JJA) spread across JJA 2008 and 2009. The cases are initialised using Met Office operational global NWP analyses valid at 12:00 UTC and are chosen so that subsequent start dates are separated by 14 days to minimise the synoptic correlation between cases. Each case is run at $\mathrm{N} 320$ resolution for a period of 5 days.

Figure 8 illustrates a comparison between the mean $24 \mathrm{~h}$ forecast $(\mathrm{T}+24)$ screen-level temperature from the 10 GA3.0/GL3.0 and GA3.1/GL3.1 cases during JJA. GA3.1/GL3.1 is significantly warmer than GA3.0/GL3.0 over Antarctica, due to the longer tail in the stability function used for stable boundary layers. In the Northern Hemisphere, there is a cooling over land in Europe and North America, which we can see reduces the warm bias present in GA3.0/GL3.0. Sensitivity tests have shown that the land surface is systematically cooler with the single amalgamated tile rather than 9 separate tiles, whilst the other land and boundary layer changes contribute to the total signal in a non-trivial way. Figure 9a shows the verification of these fields against land-based surface observations in the Northern Hemisphere as a function of forecast range. This confirms that after $24 \mathrm{~h}$, the GA3.1/GL3.1 bias is very close to zero, whilst the GA3.0/GL3.0 bias is between $0.1-0.2{ }^{\circ} \mathrm{C}$ and is up to $0.3^{\circ} \mathrm{C}$ after 5 days. Furthermore, the forecasts valid at 18:00 UTC and 00:00 UTC (T+12, 18, 36, 42 etc.) have a warm bias of about $0.5^{\circ} \mathrm{C}$ in GA3.1/GL3.1. This is exacerbated in GA3.0/GL3.0, which as with 12:00 UTC is between 0.2 and $0.5^{\circ} \mathrm{C}$ warmer than GA3.1/GL3.1. Figure $9 \mathrm{~b}$ shows verification of the $\mathrm{T}+24$ temperature profile against radiosondes released from Northern Hemisphere land stations. As expected, the main difference is constrained to the lower troposphere, since the vast majority of differences between the GA3.0/GL3.0 and GA3.1/GL3.1 configurations described in Sect. 5 are in the land surface model and the boundary layer scheme. As in Fig. 9a, we see that GA3.0/GL3.0 is warmer near the surface and the biases at $925 \mathrm{hPa}$ are roughly consistent with the screen-level results. At $1000 \mathrm{hPa}$, however, biases are either side of zero with the magnitude of the bias in GA3.1/GL3.1 being only marginally smaller than that in GA3.0/GL3.0. Figure 10 shows the $\mathrm{T}+24$ screenlevel temperature from GA3.0/GL3.0 and GA3.1/GL3.1 during DJF. As with the JJA results in Fig. 8, we see a significant warming near the winter pole and an average cooling over land in the summer hemisphere. Other near-surface forecast fields from GA3.1/GL3.1 have correlated improvements when compared with GA3.0/GL3.0, such as a decreased negative bias in pressure at mean sea level over Northern Hemisphere land in JJA (not shown). It is for this reason that GA3.1/GL3.1 rather than GA3.0/GL3.0 has been 

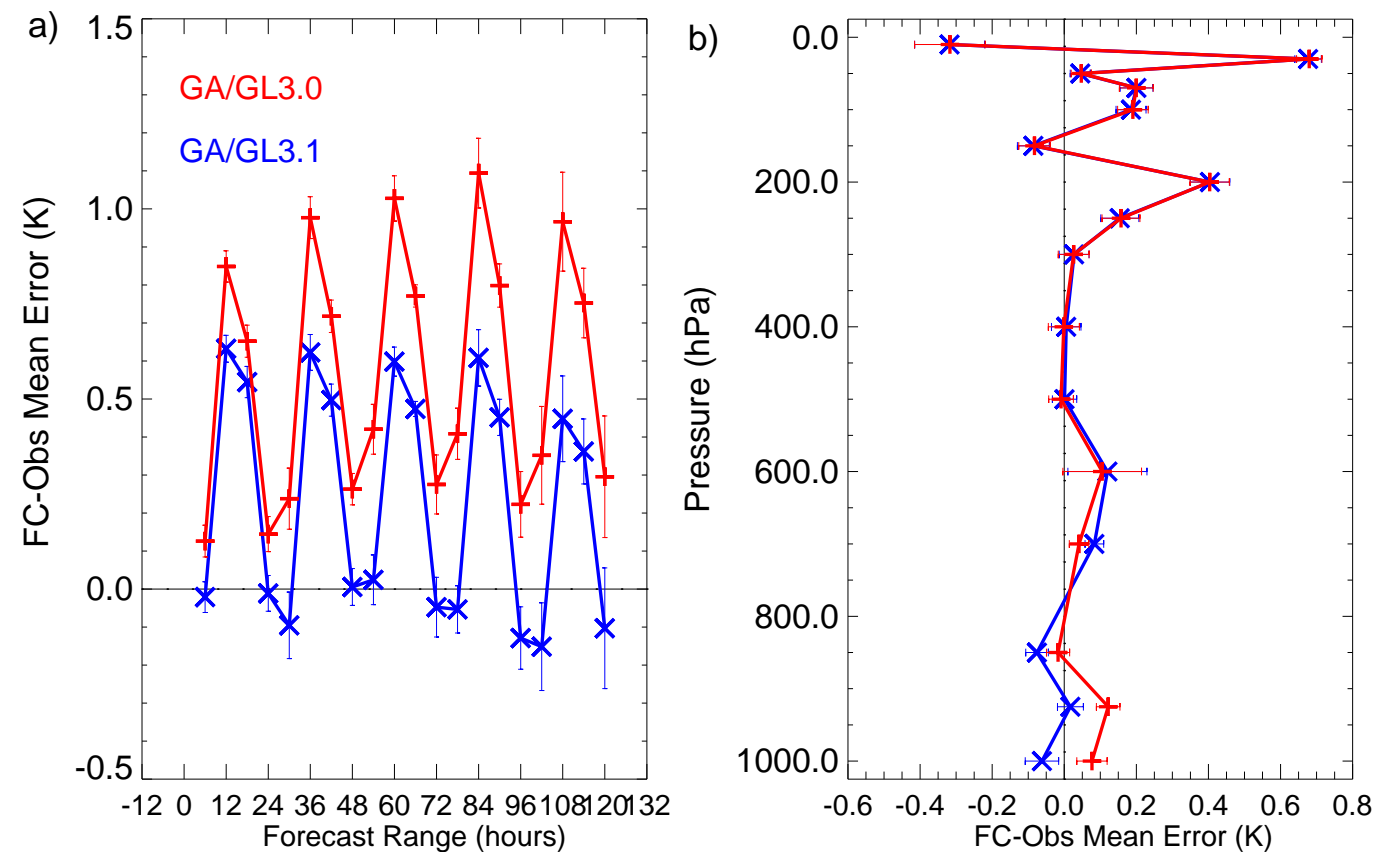

Fig. 9. Mean forecast error for $1.5 \mathrm{~m}$ temperature as a function of forecast range (a) and radiosonde temperature profiles after a $24 \mathrm{~h}$ forecast (b) from the 10 N320 NWP case studies in JJA. These errors are meaned over all land-based observations in the extra-tropical Northern Hemisphere $\left(20^{\circ}-90^{\circ} \mathrm{N}\right)$.
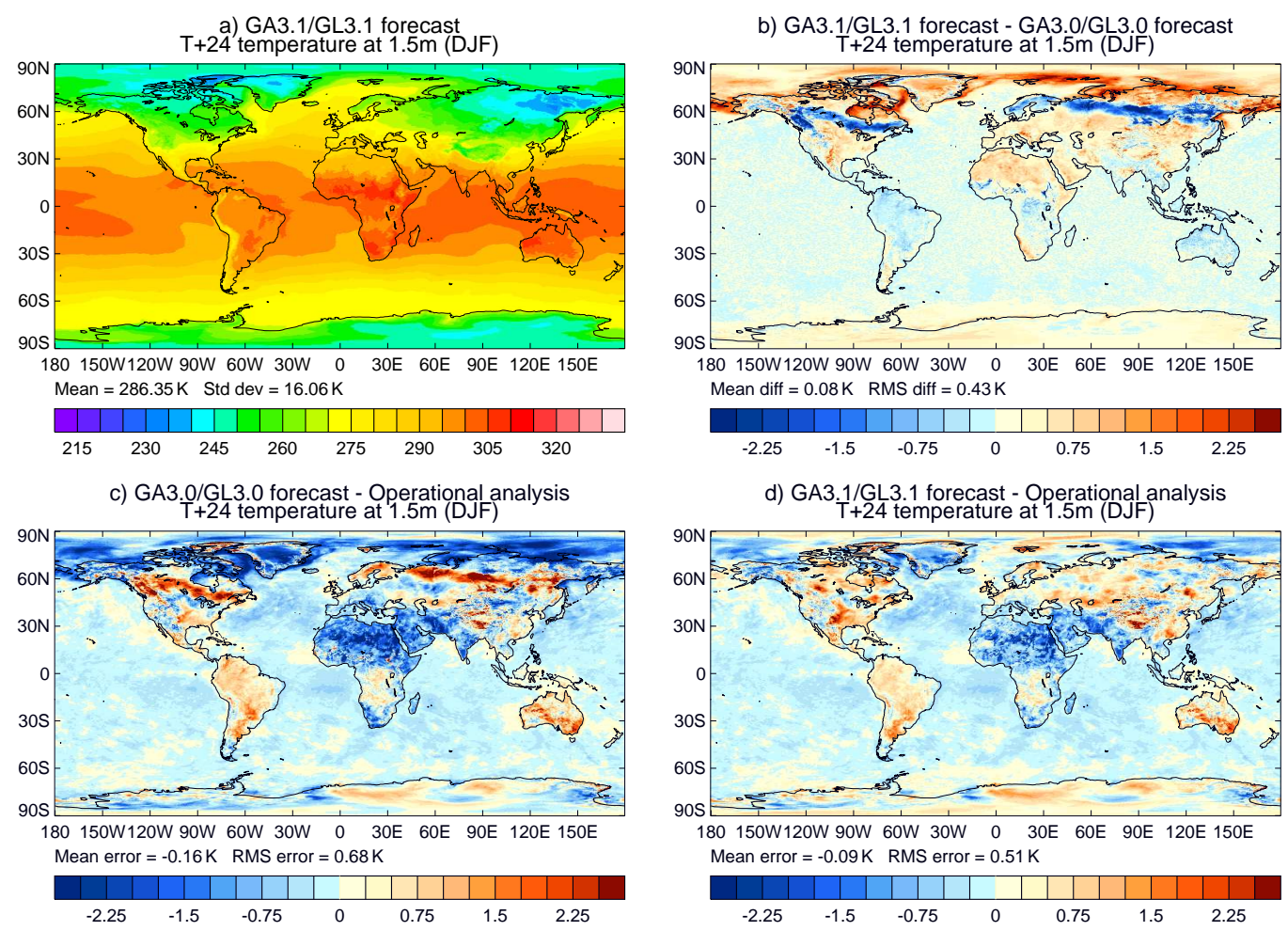

Fig. 10. Mean $24 \mathrm{~h}$ forecast $1.5 \mathrm{~m}$ temperatures from the $10 \mathrm{~N} 320$ NWP case studies in DJF using the same format as Fig. 8. 
implemented in the deterministic global forecast component of the Met Office operational NWP suite. It is worth noting, however, that the initial analyses used in these case studies were generated by a system using surface and boundary layer parametrizations much closer to those in GA3.1/GL3.1 than GA3.0/GL3.0. There is a possibility that this is related to the relative good performance of GA3.1/GL3.1 when initialised from these analyses, and in particular the soil moisture analyses that at the time used only screen-level observations of temperature and humidity to infer errors in the soil moisture (Best and Maisey, 2002). We are currently performing full NWP system trials of GA3.0/GL3.0 and GA3.1/GL3.1, including lower resolution trials run over several months, which will allow the model's analysis cycle to respond to the changes in model characteristics. This will help us to assess the true relative benefits of GA3.0/GL3.0 and GA3.1/GL3.1 in NWP systems and provide insight into how best to resolve the differences between the two configurations in the coming year.

\section{Summary and conclusions}

The primary purpose of this paper is to provide a detailed description of the scientific formulation of Global Atmosphere 3.0 and Global Land 3.0 (GA3.0/GL3.0) and the related Global Atmosphere 3.1 and Global Land 3.1 (GA3.1/GL3.1) configurations, for those utilising or contributing to them throughout the MetUM and JULES communities. We have presented results from some initial assessments showing encouraging performance of GA3.0/GL3.0 in atmosphere/landonly climate integrations, but have shown that GA3.1/GL3.1 performs better in NWP case studies initialised from Met Office operational analyses. We have listed the primary applications in which the Met Office have either implemented GA3.0/GL3.0 or GA3.1/GL3.1 or plans to do so.

We have also discussed the potential benefits of a unified and open development process. By unifying the Global Atmosphere, future enhancements will only be included if they prove acceptable across all timescales. The resulting configuration will, therefore, have a higher standard of scientific integrity due to being verified against real-time observations, atmospheric data assimilation analyses and high quality long time-series climatology datasets. Also, using this combined framework to investigate model problems or deficiencies will provide a better understanding of the underlying processes and allow us to develop robust and scientifically sound solutions. Adopting the configuration throughout the Met Office's operational forecasting and climate research activities will contribute to one of its wider aims of constructing a truly seamless operational weather and climate service. Finally, by assessing and documenting the performance of the configuration coupled to other Earth System component models and data assimilation systems, from timescales of days to decades ahead and across horizontal resolutions from N96 (approximately $135 \mathrm{~km}$ ) to N512 (25 km) and above, we aim to provide a trusted configuration that can be used for research within the Met Office, UK academia and the growing community of MetUM collaborators around the world.

Acknowledgements. MB, DC, PF, CH, GM, WM-O, MP, MR, AS and KW were supported by the Joint DECC/Defra Met Office Hadley Centre Climate Programme (GA01101). The development of the Global Atmosphere/Land configurations was possible only through the hard work of a large number of people, both within and outside the Met Office, that exceeds the list of authors.

Intellectual property.

Due to intellectual property right restrictions, we cannot provide either the source code or documentation papers for the MetUM or JULES.

Obtaining the MetUM.

The Met Office Unified Model is available for use under licence. A number of research organisations and national meteorological services use the MetUM in collaboration with the Met Office to undertake basic atmospheric process research, produce forecasts, develop the MetUM code and build and evaluate Earth System models. For further information on how to apply for a licence see http: //www.metoffice.gov.uk/research/collaboration/um-collaboration Obtaining JULES.

JULES is available under licence free of charge. Please contact a JULES partner institution for permission to use JULES for research purposes. For a list of JULES partners see http://www.jchmr.org/jules/licence.html

Copyright statement.

This work is distributed under the Creative Commons Attribution 3.0 License together with an author copyright. This license does not conflict with the regulations of the Crown Copyright.

Edited by: J. C. Hargreaves

\section{References}

Abel, S. J. and Shipway, B. J.: A comparison of cloud-resolving model simulations of trade wind cumulus with aircraft observations taken during RICO, Q. J. Roy. Meteorol. Soc., 133, 781794, 2007.

Abel, S. J., Walters, D. N., and Allen, G.: Evaluation of stratocumulus cloud prediction in the Met Office forecast model during VOCALS-REx, Atmos. Chem. Phys., 10, 10541-10559, doi:10.5194/acp-10-10541-2010, 2010.

Adler, R. F., Huffman, G. J., Chang, A., Ferraro, R., Xie, P.-P., Janowiak, J., Rudolf, B., Schneider, U., Curtis, S., Bolvin, D., Gruber, A., Susskind, J., Arkin, P., and Nelkin, E.: The version-2 Global Precipitation Climatology Project (GPCP) monthly precipitation analysis (1979-present), J. Hydrometeor., 4, 1147$1167,2003$.

Allan, R. and Ansell, T.: A new globally complete monthly historical gridded mean sea level pressure dataset (HadSLP2): 18502004, J. Climate, 19, 5816-5842, 2006.

Arakawa, A. and Lamb, V. R.: Computational design of the basic dynamic processes of the UCLA general circulation model, Methods Comput. Phys., 17, 173-265, 1977.

Arribas, A., Glover, M., Maidens, A., Peterson, K., Gordon, M., MacLachlan, C., Graham, R., Fereday, D., Camp, J., Scaife, 
A. A., Xavier, P., McLean, P., Colman, A., and Cusack, S.: The GloSea4 ensemble prediction system for seasonal forecasting, Mon. Weather Rev., 139, 1891-1910, 2011.

Arribas, A. et al.: A fully resolved stratosphere and sea-ice initialisation: upgrades to the GloSea4 seasonal forecasting system, in preparation, 2011.

Balsamo, G., Pappenberger, F., Dutra, E., Viterbo, P., and van den Hurk, B.: A revised land hydrology in the ECMWF model: a step towards daily water flux prediction in a fully-closed water cycle, Hydrol. Process., 25, 1046-1054, 2011.

Barker, H. W. and Li, Z.: Improved simulation of clear-sky shortwave radiative transfer in the CCC-GCM, J. Climate, 8, 22132223, 1995.

Beard, K. V.: Terminal velocity and shape of cloud and precipitation drops aloft, J. Atmos. Sci., 33, 851-864, 1976.

Beljaars, A. C. M. and Holtslag, A. A. M.: Flux parametrization over land surfaces for atmospheric models, J. Appl. Meteorol., 30, 327-341, 1991.

Beljaars, A. C. M. and Viterbo, P.: Role of the boundary layer in a numerical weather prediction model., in: Clear and cloudy boundary layers, edited by: Holtslag, A. A. M. and Duynkerke, P. G., Royal Netherlands Academy of Arts and Sciences, Amsterdam, 1998.

Berrisford, P., Dee, D., Fielding, K., Fuentes, M., Kållberg, P., Kobayashi, S., and Uppala, S.: The ERA-Interim archive, Tech. Rep. 1, ERA report series, ECMWF, Reading, UK, 2009.

Best, M. J.: Representing urban areas within operational numerical weather prediction models, Bound.-Lay. Meteorol., 114, 91-109, 2005.

Best, M. J. and Maisey, P. E.: A physically based soil moisture nudging scheme, Tech. Rep. 35, Hadley Centre, Met Office, Bracknell, UK, 2002.

Best, M. J., Pryor, M., Clark, D. B., Rooney, G. G., Essery, R .L. H., Ménard, C. B., Edwards, J. M., Hendry, M. A., Porson, A., Gedney, N., Mercado, L. M., Sitch, S., Blyth, E., Boucher, O., Cox, P. M., Grimmond, C. S. B., and Harding, R. J.: The Joint UK Land Environment Simulator (JULES), model description Part 1: Energy and water fluxes, Geosci. Model Dev., 4, 677699, doi:10.5194/gmd-4-677-2011, 2011.

Beven, K. and Kirkby, M. J.: A physically based, variable contributing area model of basin hydrology, Hydrol. Sci. B., 24, 43-69, 1979.

Bosilovich, M. G.: NASA's modern era retrospectiveanalysis for research and applications: Integrating Earth observations, Earthzine, http://www.earthzine.org/2008/09/26/ nasas-modern-era-retrospective-analysis, last access: 12 April 2011, 2008.

Bowler, N. E., Arribas, A., Mylne, K. R., Robertson, K. B., and Beare, S. E.: The MOGREPS short-range ensemble prediction system, Q. J. Roy. Meteorol. Soc., 134, 703-722, 2008.

Brohan, P., Kennedy, J. J., Harris, I., Tett, S. F. B., and Jones, P. D.: Uncertainty estimates in regional and global observed temperature changes: a new dataset from 1850, J. Geophys. Res., 111, D12106, doi:10.1029/2005JD006548, 2006.

Brown, A. R. and Webster, S.: Orographic flow-blocking scheme characteristics., Q. J. Roy. Meteorol. Soc., 130, 3015-3028, 2004.

Brown, A. R., Beare, R. J., Edwards, J. M., Lock, A. P., Keogh, S. J., Milton, S. F., and Walters, D. N.: Upgrades to the boundary-layer scheme in the Met Office numerical weather prediction model, Bound.-Lay. Meteorol., 128, 117-132, 2008.

Bushell, A. C., Wilson, D. R., and Gregory, D.: A description of cloud production by non-uniformly distributed processes, Q. J. Roy. Meteorol. Soc., 129, 1435-1455, 2003.

Charney, J. G. and Phillips, N. A.: Numerical integration of the quasi-geostrophic equations for barotropic and simple baroclinic flows, J. Meteor., 10, 71-99, 1953.

Clapp, R. B. and Hornberger, G. M.: Empirical equations for some soil hydraulic properties, Water Resour. Res., 14, 601-604, 1978.

Clark, D. B., Mercado, L. M., Sitch, S., Jones, C. D., Gedney, N., Best, M. J., Pryor, M., Rooney, G. G., Essery, R. L. H., Blyth, E., Boucher, O., Harding, R. J., Huntingford, C., and Cox, P. M.: The Joint UK Land Environment Simulator (JULES), model description - Part 2: Carbon fluxes and vegetation dynamics, Geosci. Model Dev., 4, 701-722, doi:10.5194/gmd-4-701-2011, 2011.

Clough, S. A., Kneizys, F. X., and Davies, R. W.: Line shape and the water vapor continuum, Atmos. Res., 23, 229-241, 1989.

Coleman, K. and Jenkinson, D. S.: RothC-26.3, a model for the turnover of carbon in soil: Model description and user's guide, Tech. rep., Lawes Agricultural Trust, IACR Rothamsted, Harpenden, UK, 1999.

Collins, W. J., Bellouin, N., Doutriaux-Boucher, M., Gedney, N., Hinton, T., Jones, C. D., Liddicoat, S., Martin, G., O'Connor, F., Rae, J., Senior, C., Totterdell, I., Woodward, S., Reichler, T., Kim, J., and Halloran, P.: Evaluation of the HadGEM2 model, Tech. Rep. 74, Hadley Centre, Met Office, Exeter, UK, 2008.

Cox, P.: Description of the TRIFFID dynamic global vegetation model, Tech. Rep. 24, Hadley Centre, Met Office, Bracknell, UK, 2001.

Cox, P., Betts, R., Jones, C., Spall, S., and Totterdell, I.: Acceleration of global warming due to carbon-cycle feedbacks in a coupled climate model, Nature, 408, 184-187, 2000.

Cox, P. M., Betts, R. A., Bunton, C. B., Essery, R., Rowntree, P. R., , and Smith, J.: The impact of new land surface physics on the GCM simulation of climate and climate sensitivity, Clim. Dynam., 15, 183-203, 1999.

Cullen, M. J. P.: The unified forecast/climate model, Meteor. Mag., 122, 81-94, 1993.

Cusack, S., Slingo, A., Edwards, J. M., and Wild, M.: The radiative impact of a simple aerosol climatology on the Hadley Centre atmospheric GCM, Q. J. Roy. Meteorol. Soc., 124, 2517-2526, 1998.

Cusack, S., Edwards, J. M., and Crowther, J. M.: Investigating $k$ distribution methods for parameterizing gaseous absorption in the Hadley Centre climate model, J. Geophys. Res., 104, 20512057, 1999.

Davies, T., Cullen, M. J. P., Malcolm, A. J., Mawson, M. H., Staniforth, A., White, A. A., and Wood, N.: A new dynamical core for the Met Office's global and regional modelling of the atmosphere, Q. J. Roy. Meteorol. Soc., 131, 1759-1782, 2005.

Derbyshire, S. H., Maidens, A. V., Milton, S. F., Stratton, R. A., and Willett, M. R.: Adaptive detrainment in a convective parametrization., Q. J. Roy. Meteorol. Soc., doi:10.1002/qj.875, in press, 2011.

Dharssi, I., Vidale, P. L., Verhoef, A., Macpherson, B., Jones, C., and Best, M.: New soil physical properties implemented in the Unified Model at PS18, Tech. Rep. 528, Forecasting R\&D, Met 
Office, Exeter, UK, 2009.

Donlon, C. J., Martin, M., Stark, J. D., Roberts-Jones, J., and Fiedler, E.: The Operational Sea Surface Temperature and Sea Ice Analysis (OSTIA) system, Remote Sens. Environ., doi:10.1016/j.rse.2010.10.017, in press, 2011.

Dyer, A. J. and Hicks, B. B.: Flux-gradient relationships in the constant flux layer, Q. J. Roy. Meteorol. Soc., 96, 715-721, 1970.

Edwards, J. M.: Efficient calculation of infrared fluxes and cooling rates using the two-stream equations, J. Atmos. Sci., 53, 19211932, 1996.

Edwards, J. M. and Slingo, A.: Studies with a flexible new radiation code. I: Choosing a configuration for a large-scale model, Q. J. Roy. Meteorol. Soc., 122, 689-719, 1996.

Edwards, J. M., Havemann, S., Thelen, J.-C., and Baran, A. J.: A new parametrization for the radiative properties of ice crystals: Comparison with existing schemes and impact in a GCM, Atmos. Res., 83, 19-35, 2007.

Essery, R. L. H., Best, M. J., Betts, R. A., Cox, P. M., and Taylor, C. M.: Explicit representation of subgrid heterogeneity in a GCM land surface scheme, J. Hydrometeorol., 4, 530-543, 2003.

Falloon, P. D. and Betts, R. A.: The impact of climate change on global river flow in HadGEM1 simulations, Atmos. Sci. Lett., 7, 62-68, 2006.

Fritsch, J. M. and Chappell, C. F.: Numerical prediction of convectively driven mesoscale pressure systems. Part I: convective parameterization, J. Atmos. Sci., 37, 1722-1733, 1980.

Gedney, N. and Cox, P. M.: The sensitivity of global climate model simulations to the representation of soil moisture heterogeneity, J. Hydrometeorol., 4, 1265-1275, 2003.

Gedney, N., Cox, P. M., and Huntingford, C.: Climate feedback from wetland methane emissions, Geophys. Res. Lett., 31, L20503, doi:10.1029/2004GL020919, 2004.

Global Soil Data Task: Global soil data products CD-ROM (IGBP-DIS), CD-ROM, http://www.daac.ornl.gov, International Geosphere-Biosphere Programme, Data and Information System, Potsdam, Germany. Available from Oak Ridge National Laboratory Distributed Active Archive Center, Oak Ridge, TN, last access: 12 April 2011, 2000.

Godfrey, J. S. and Beljaars, A. C. M.: On the turbulent fluxes of buoyancy, heat and moisture at the air-sea interface at low wind speeds, J. Geophys. Res., 96, 22043-22048, 1991.

Grant, A. L. M.: Cloud-base fluxes in the cumulus-capped boundary layer, Q. J. Roy. Meteorol. Soc., 127, 407-421, 2001.

Grant, A. L. M. and Brown, A. R.: A similarity hypothesis for shallow-cumulus transports, Q. J. Roy. Meteorol. Soc., 125, 1913-1936, 1999.

Gregory, D. and Allen, S.: The effect of convective downdraughts upon NWP and climate simulations, in: Nineth conference on numerical weather prediction, Denver, Colorado, 122-123, 1991.

Gregory, D. and Rowntree, P. R.: A massflux convection scheme with representation of cloud ensemble characteristics and stability dependent closure, Mon. Weather Rev., 118, 1483-1506, 1990.

Gregory, D., Kershaw, R., and Inness, P. M.: Parametrization of momentum transport by convection II: Tests in single-column and general circulation models, Q. J. Roy. Meteorol. Soc., 123, 1153-1183, 1997.

Gregory, D., Shutts, G. J., and Mitchell, J. R.: A new gravity-wavedrag scheme incorporating anisotropic orography and low-level wave breaking: Impact upon the climate of the UK Meteorological Office Unified Model, Q. J. Roy. Meteorol. Soc., 124, 463493, 1998.

HadGEM2 Development Team: Martin, G. M., Bellouin, N., Collins, W. J., Culverwell, I. D., Halloran, P. R., Hardiman, S. C., Hinton, T. J., Jones, C. D., McDonald, R. E., McLaren, A. J., O’Connor, F. M., Roberts, M. J., Rodriguez, J. M., Woodward, S., Best, M. J., Brooks, M. E., Brown, A. R., Butchart, N., Dearden, C., Derbyshire, S. H., Dharssi, I., Doutriaux-Boucher, M., Edwards, J. M., Falloon, P. D., Gedney, N., Gray, L. J., Hewitt, H. T., Hobson, M., Huddleston, M. R., Hughes, J., Ineson, S., Ingram, W. J., James, P. M., Johns, T. C., Johnson, C. E., Jones, A., Jones, C. P., Joshi, M. M., Keen, A. B., Liddicoat, S., Lock, A. P., Maidens, A. V., Manners, J. C., Milton, S. F., Rae, J. G. L., Ridley, J. K., Sellar, A., Senior, C. A., Totterdell, I. J., Verhoef, A., Vidale, P. L., and Wiltshire, A.: The HadGEM2 family of Met Office Unified Model climate configurations, Geosci. Model Dev., 4, 723-757, doi:10.5194/gmd-4-723-2011, 2011.

Haywood, J. M., Allan, R. P., Culverwell, I., Slingo, A., Milton, S., Edwards, J. M., and Clerbaux, N.: Can desert dust explain the outgoing longwave radiation anomaly over the Sahara during July 2003?, J. Geophys. Res., 110, D05105, doi:10.1029/2004JD005232, 2005.

Heming, J. T.: The impact of resolution on Met Office model predictions of tropical cyclone track and intensity, in: AMS 29th Conference on Hurricanes and Tropical Meteorology, Tucson, Arizona, 10-14th May 2010, 10C.1, 2010.

Hewitt, H. T., Copsey, D., Culverwell, I. D., Harris, C. M., Hill, R. S. R., Keen, A. B., McLaren, A. J., and Hunke, E. C.: Design and implementation of the infrastructure of HadGEM3: the nextgeneration Met Office climate modelling system, Geosci. Model Dev., 4, 223-253, doi:10.5194/gmd-4-223-2011, 2011.

Hill, P. G., Manners, J., and Petch, J. C.: Reducing noise associated with the Monte Carlo Independent Column Approximation for weather forecasting models, Q. J. Roy. Meteorol. Soc., 137, 219 228, 2011.

Hogan, R. J. and Illingworth, A. J.: Deriving cloud overlap statistics from radar, Q. J. Roy. Meteorol. Soc., 126, 2903-2909, 2000.

Hunke, E. C. and Lipscombe, W. H.: CICE: the Los Alamos sea ice model documentation and software user's manual, Version 4.0, LA-CC-06-012, Los Alamos National Laboratory, New Mexico, 2008.

Huntingford, C., Jones, R. G., Prudhomme, C., Lamb, R., Gash, J. H. C., and Jones, D. A.: Regional climate-model predictions of extreme rainfall for a changing climate, Q. J. Roy. Meteorol. Soc., 129, 1607-1621, 2003.

Jenkinson, D. S., Andrew, S. P. S., Lynch, J. M., Goss, M. J., and Tinker, P. B.: The turnover of organic carbon and nitrogen in soil, Philos. Trans. Roy. Soc. London, B329, 361-368, 1990.

Johansen, O.: Thermal conductivity of soils, Ph.D. thesis, University of Trondheim, Norway, 1975.

Jones, A., Roberts, D. L., and Slingo, A.: A climate model study of indirect radiative forcing by anthropogenic sulphate aerosols, Nature, 370, 450-453, 1994.

Jones, A., Roberts, D. L., Woodage, M. J., and Johnson, C. E.: Indirect sulphate aerosol forcing in a climate model with an interactive sulphur cycle, J. Geophys. Res., 106, 20293-20310, 2001.

Kurucz, R. L. and Bell, B.: Atomic Line Data, CD-ROM 23, Harvard Smithsonian Center for Astrophysics, Cambridge, MA, 
1995.

Lean, H. W.: Simulation of orographic rainfall in South Wales with UM Version 5.2, Tech. Rep. 70, JCMM, Met Office/University of Reading Joint Centre for Mesoscale Meteorology, Reading, 2002.

Lean, H. W., Clark, P. A., Dixon, M., Roberts, N. M., Fitch, A., Forbes, R., and Halliwell, C.: Characteristics of high-resolution versions of the Met Office Unified Model for forecasting convection over the United Kingdom, Mon. Weather Rev., 136, 34083424, 2008.

Lean, J.: Evolution of the Sun's spectral irradiance since the Maunder Minimum, Geophys. Res. Lett., 27, 2425-2428, 2000.

Legates, D. R. and Willmott, C. J.: Mean seasonal and spatial variability in global surface air temperature, Theor. Appl. Climatol., 41, 11-21, 1990.

Lock, A. P.: The numerical representation of entrainment in parametrizations of boundary layer turbulent mixing, Mon. Weather Rev., 129, 1148-1163, 2001.

Lock, A. P., Brown, A. R., Bush, M. R., Martin, G. M., and Smith, R. N. B.: A new boundary layer mixing scheme. Part I: Scheme description and single-column model tests, Mon. Weather Rev., 128, 3187-3199, 2000.

Madec, G.: NEMO ocean engine, Institut Piere-Simon Laplace (IPSL), France, No. 27, ISSN No. 1288-1619, 2008.

Manners, J.: Radiative transfer over resolved topographic features for high resolution weather prediction, Q. J. Roy. Meteorol. Soc., in press, doi:10.1002/qj.956, 2011.

Manners, J., Thelen, J.-C., Petch, J., Hill, P., and Edwards, J. M.: Two fast radiative transfer methods to improve the temporal sampling of clouds in numerical weather prediction and climate models, Q. J. Roy. Meteorol. Soc., 135, 457-468, 2009.

Marshall, J. S. and Palmer, W. M.: The distribution of raindrops with size, J. Meteor., 5, 165-166, 1948.

Martin, G. M., Ringer, M. A., Pope, V. D., Jones, A., Dearden, C., and Hinton, T. J.: The physical properties of the atmosphere in the new Hadley Centre Global Environment Model (HadGEM1). Part I: Model description and global climatology, J. Climate, 19, 1274-1301, 2006.

Martin, G. M., Milton, S. F., Senior, C. A., Brooks, M. E., Ineson, S., Reichler, T., and Kim, J.: Analysis and reduction of systematic errors through a seamless approach to modeling weather and climate, J. Climate, 23, 5933-5957, 2010.

McCabe, A. and Brown, A. R.: The role of surface heterogeneity in modelling the stable boundary layer, Bound.-Lay. Meteorol., 122, 517-534, 2007.

Mercado, L. M., Huntingford, C., Gash, J. H. C., Cox, P. M., and Jogireddy, V.: Improving the representation of radiative interception and photosynthesis for climate model applications, Tellus, B59, 553-565, 2007.

Milton, S., Brooks, M., Lock, A., Whelan, E., and Wilson, D.: HadGEM1 physics for the global NWP model (Cycle G34) improvements to boundary layer, large scale precipitation, convection and Saharan albedo, Tech. Rep. 458, Forecasting R\&D, Met Office, Exeter, UK, 2005.

Milton, S. F., Greed, G., Brooks, M. E., Haywood, J., Johnson, B., Allan, R. P., Slingo, A., and Grey, W. M. F.: Modeled and observed atmospheric radiation balance during the West African dry season: Role of mineral dust, biomass burning aerosol, and surface albedo, J. Geophys. Res., 113, D00C02, 2008.
Minobe, S., Kuwano-Yoshida, A., Komori, N., Xie, S.-P., and Small, R. J.: Influence of the Gulf Stream on the troposphere, Nature, 452, 206-209, 2008.

Mlawer, E. J., Clough, S. A., Brown, P. D., and Tobin, D. C.: Recent developments in the water vapor continuum, in: Nineth ARM Science Team meeting, San Antonio, Texas, 22-26 ${ }^{\text {th }}$ March 1999, edited by: Burleigh, N. and Carrothers, D., 1-6, 1999.

Morcrette, C. J. and Petch, J. C.: Analysis of prognostic cloud scheme increments in a climate model, Q. J. Roy. Meteorol. Soc., 136, 2061-2073, 2010.

Nachtergaele, F., van Velthuizen, H., Verelst, L., Batjes, N., Dijkshoorn, K., van Engelen, V., Fischer, G., Jones, A., Montanarella, L., Petri, M., Prieler, S., Teixeira, E., Wiberg, D., and Shi, X.: Harmonized World Soil Database (version 1.0), FAO, Rome, Italy and IIASA, Laxenburg, Austria, 2008.

Nicholls, S.: The dynamics of stratocumulus: Aircraft observations and comparisons with a mixed layer model, Q. J. Roy. Meteorol. Soc., 110, 783-820, 1984.

Oki, T.: Validating the runoff from LSP-SVAT models using a global river routing network by one degree mesh, in: AMS 13th Conference on Hydrology, Long Beach, California, 2-7th February 1997, 319-322, 1997.

Oki, T. and Sud, Y. D.: Design of Total Runoff Integrating Pathways (TRIP) - A global river channel network, Earth Interact., 2, 1-36, 1998.

Pincus, R., Barker, H. W., and Morcrette, J. J.: A fast, flexible, approximate technique for computing radiative transfer in inhomogeneous cloud fields, J. Geophys. Res., 108, 4376, doi:10.1029/2002JD003322, 2003.

Posselt, R. and Lohmann, U.: Introduction of prognostic rain in ECHAM5: design and single column model simulations., Atmos. Chem. Phys., 8, 2949-2963, doi:10.5194/acp-8-2949-2008, 2008.

Räisänen, P., Barker, H. W., Khairoutdinov, M. F., Li, J., and Randall, D. A.: Stochastic generation of subgrid-scale cloudy columns for large-scale models, Q. J. Roy. Meteorol. Soc., 130, 2047-2067, 2004

Rawlins, F., Ballard, S. P., Bovis, K. J., Clayton, A. M., Li, D., Inverarity, G. W., Lorenc, A. C., and Payne, T. J.: The Met Office global four-dimensional variational data assimilation scheme, Q. J. Roy. Meteorol. Soc., 133, 347-362, 2007.

Redelsperger, J.-L., Guichard, F., and Mondon, S.: A parametrization of mesoscale enhancement of surface fluxes for large-scale models, J. Climate, 13, 402-421, 2000.

Rothman, L. S., Barbe, A., Benner, D. C., Brown, L. R., CamyPeyret, C., Carleer, M. R., Chance, K., Clerbaux, C., Dana, V., Devi, V. M., Fayt, A., Flaud, J.-M., Gamache, R. R., Goldman, A., Jacquemart, D., Jucks, K. W., Lafferty, W. J., Mandin, J.Y., Massie, S. T., Nemtchinov, V., Newnham, D. A., Perrin, A., Rinsland, C. P., Schroeder, J., Smith, K. M., Smith, M. A. H., Tang, K., Toth, R. A., Auwera, J. V., Varanasi, P., and Yoshino, K.: The HITRAN molecular spectroscopic database: edition of 2000 including updates through 2001, J. Quant. Spectrosc. Ra., 82, 5-44, 2003.

Sachidananda, M. and Zrnić, D. S.: Differential propagation phase shift and rainfall rate estimation, Radio Sci., 21, 235-247, 1986.

Scaife, A. A., Butchart, N., Warner, C. D., and Swinbank, R.: Impact of a spectral gravity wave parametrization on the stratosphere in the Met Office Unified Model, J. Atmos. Sci., 59, 
1473-1489, 2002.

Scaife, A. A., Copsey, D., Gordon, C., Harris, C., Hinton, T., Keeley, S., O’Neill, A., Roberts, M., and Williams, K.: Improved Atlantic blocking in a climate model, Geophys. Res. Lett., submitted, 2011.

Senior, C. A., Arribas, A., Brown, A. R., Cullen, M. J. P., Johns, T. C., Martin, G. M., Milton, S. F., Smith, D. M., Webster, S., and Williams, K. D.: Synergies between numerical weather prediction and general circulation climate models, in: The development of atmospheric general circulation models, edited by: Donner, L., Schubert, W., and Somerville, R., Cambridge University Press, Cambridge, UK, 2010.

Shaffrey, L. C., Stevens, I., Norton, W. A., Roberts, M. J., Vidale, P.-L., Harle, J. D., Jrrar, A., Stevens, D. P., Woodage, M. J., Demory, M.-E., Donners, J., Clarke, D. B., Clayton, A., Cole, J. W., Wilson, S. S., Connolley, W. M., Davies, T. M., Iwi, A. M., Johns, T. C., King, J. C., New, A. L., Slingo, J. M., Slingo, A., Steenman-Clark, L., and Martin, G. M.: U.K. HiGEM: the new U.K. High-resolution Global Environment Model - Model description and basic evaluation, J. Climate, 22, 1861-1896, 2009.

Smith, D. M., Cusack, S., Colman, A. W., Folland, C. K., Harris, G. R., and Murphy, J. M.: Improved surface temperature prediction for the coming decade from a global climate model, Science, 317, 769-799, 2007.

Smith, R. N. B.: A scheme for predicting layer cloud and their water content in a general circulation model, Q. J. Roy. Meteorol. Soc., 116, 435-460, 1990

Staniforth, A., Wood, N., and Côté, J.: A simple comparison of four physics-dynamics coupling schemes, Mon. Weather Rev., 130, 3129-3135, 2002.

Stratton, R. A., Stirling, A., and Derbyshire, S.: Changes and developments to Convective Momentum Transport (CMT) parametrization based on analysis of CRM and SCM, Tech. Rep. 530, Forecsating R\&D, Met Office, Exeter, UK, 2009.

Taylor, K. E., Stouffer, R. J., and Meehl, G. A.: A Summary of the CMIP5 Experiment Design, http://cmip-pcmdi.llnl.gov/cmip5/ docs/Taylor_CMIP5_design.pdf, last access: 12 April 2011, 2009.

Tripoli, G. J. and Cotton, W. R.: A numerical investigation of several factors contributing to the observed variable intensity of deep convection over south Florida, J. Appl. Meteorol., 19, 10371063,1980

Untch, A. and Simmons, A. J.: Increased stratospheric resolution in the ECMWF forecasting system, ECMWF Newsletter 82, ECMWF, Reading, UK, 1999.

Uppala, S. M., Kållberg, P. W., Simmons, A. J., Andrae, U., V. Da Costa Bechtold, Fiorino, M., Gibson, J. K., Haseler, J., Hernandez, A., Kelly, G. A., Li, X., Onogi, K., Saarinen, S., Sokka, N., Allan, R. P., Andersson, E., Arpe, K., Balmaseda, M. A., Beljaars, A. C. M., van de Berg, L., Bidlot, J., Bormann, N., Caires, S., Chevallier, F., Dethof, A., Dragosavac, M., Fisher, M., Fuentes, M., Hagemann, S., Hólm, E., Hoskins, B. J., Isaksen, L., Janssen, P. A. E. M., Jenne, R., Mcnally, A. P., Mahfouf, J.-F., Morcrette, J.-J., Rayner, N. A., Saunders, R. W., Simon, P., Sterl, A., Trenberth, K. E., Untch, A., Vasiljevic, D., Viterbo, P., and Woollen, J.: The ERA-40 re-analysis, Q. J. Roy. Meteorol. Soc., 131, 2961-3012, 2005.
Valcke, S.: OASIS3 user guide (prism_2-5), Tech. Rep. 3, Programme for integrated earth system modelling (PRISM) support initiative, last access: 12 April 2011, 2006.

van Genuchten, M. T.: A closed-form equation for predicting the hydraulic conductivity of unsaturated soils, Soil Sci. Soc. Am. J., 44, 892-898, 1980.

Viterbo, P., Beljaars, A. C. M., Mahouf, J.-F., and Teixeira, J.: The representation of soil moisture freezing and its impact on the stable boundary layer, Q. J. Roy. Meteorol. Soc., 125, 2401-2426, 1999.

Warner, C. D. and McIntyre, M. E.: An ultrasimple spectral parametrization for nonorographic gravity waves, J. Atmos. Sci., 58, 1837-1857, 2001.

Webster, S., Brown, A. R., Cameron, D. R., and Jones, C. P.: Improvements to the representation of orography in the Met Office Unified Model, Q. J. Roy. Meteorol. Soc., 129, 1989-2010, 2003.

Wells, H., Webster, S., and Brown, A.: The effect of rotation on the pressure drag force produced by flow around long mountain ridges, Q. J. Roy. Meteorol. Soc., 131, 1321-1338, 2005.

Wentz, F. J. and Spencer, R. W.: SSM/I rain retrievals within a unified all-weather ocean algorithm, J. Atmos. Sci., 55, 1613-1627, note: SSM/I data are produced by Remote Sensing Systems and sponsored by the NASA Earth Science MEaSUREs DISCOVER Project. Data are available at www.remss.com, last access: 12 April 2011, 1998.

Wielicki, B. A., Barkstrom, B. R., Harrison, E. F., Lee, R. B., Smith, G. L., and Cooper, J. E.: Clouds and the Earth's Radiant Energy System (CERES): An Earth observing system experiment, B. Am. Meteorol. Soc., 77, 853-868, 1996.

Wilson, D. R. and Ballard, S. P.: A microphysically based precipitation scheme for the UK Meteorological Office Unified Model, Q. J. Roy. Meteorol. Soc., 125, 1607-1636, 1999.

Wilson, D. R., Bushell, A. C., Kerr-Munslow, A. M., Price, J. D., and Morcrette, C. J.: PC2: A prognostic cloud fraction and condensation scheme. I: Scheme description., Q. J. Roy. Meteorol. Soc., 134, 2093-2107, 2008a.

Wilson, D. R., Bushell, A. C., Kerr-Munslow, A. M., Price, J. D., Morcrette, C. J., and Bodas-Salcedo, A.: PC2: A prognostic cloud fraction and condensation scheme. II: Climate model simulations., Q. J. Roy. Meteorol. Soc., 134, 2109-2125, 2008 b.

Wood, N., Diamantakis, M., and Staniforth, A.: A monotonicallydamping second-order-accurate unconditionally-stable numerical scheme for diffusion, Q. J. Roy. Meteorol. Soc., 133, 15591573, 2007.

Xie, P. and Arkin, P. A.: Global precipitation: A 17-year monthly analysis based on gauge observations, satellite estimates, and numerical model outputs, B. Am. Meteorol. Soc., 78, 2539-2558, 1997.

Zhong, W. and Haigh, J. D.: An efficient and accurate correlated-k parameterization of infrared radiative transfer for tropospherestratosphere-mesosphere GCMs, Atmos. Sci. Lett., 1, 125-135, 2000.

Zhong, W., Osprey, S. M., Gray, L. J., and Haigh, J. D.: Influence of the prescribed solar spectrum on calculations of atmospheric temperature, Geophys. Res. Lett., 35, L22813, doi:10.1029/2008GL035993, 2008. 